\title{
Enhanced Artificial Enzyme Activities on the Reconstructed Sawtoothlike Nanofacets of Pure and Pr-Doped Ceria Nanocubes
}

Lei Jiang,* Miguel Tinoco, Susana Fernández-García, Yujiao Sun, Mariia Traviankina, Pengli Nan, Qi Xue, Huiyan Pan, Almudena Aguinaco, Juan M. González-Leal, Ginesa Blanco, Eduardo Blanco, Ana B. Hungría, Jose J. Calvino, and Xiaowei Chen*

Cite This: ACS Appl. Mater. Interfaces 2021, 13, 38061-38073

Read Online

ACCESS | Llll Metrics \& More | 回 Article Recommendations | sl Supporting Information

ABSTRACT: In this work, a simple one-step thermal oxidation process was established to achieve a significant surface increase in $\{110\}$ and $\{111\}$ nanofacets on well-defined, pure and Pr-doped, ceria nanocubes. More importantly, without changing most of the bulk properties, this treatment leads to a remarkable boost of their enzymatic activities: from the oxidant (oxidase-like) to antioxidant (hydroxyl radical scavenging) as well as the paraoxon degradation (phosphatase-like) activities. Such performance improvement might be due to the thermally generated sawtoothlike $\{111\}$ nanofacets and defects, which facilitate the oxygen mobility and the formation of oxygen vacancies on the surface. Finally, possible mechanisms of nanoceria as artificial enzymes have been proposed

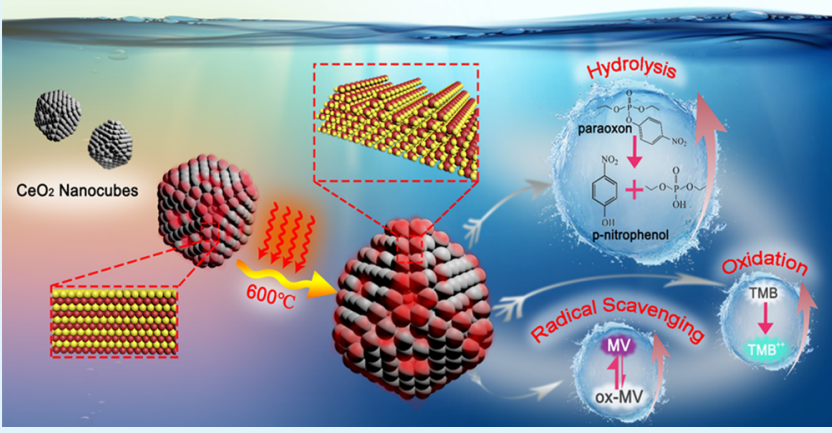
in this manuscript. Considering the potential application of ceria as artificial enzymes, this thermal treatment may enable the future design of highly efficient nanozymes without changing the bulk composition.

KEYWORDS: ceria, nanocubes, Pr-doping, oxidation treatment, artificial enzyme, nanofacets

\section{INTRODUCTION}

Natural enzymes play a crucial role in catalyzing almost all biochemical reactions in biological systems. Their catalytic efficiency is extraordinary in terms of selectivity, yield, and reaction rate. Because of their restraint in denaturation conditions, stability and cost, for a long time people have been intending to find a substitution of enzymes using inorganic materials, that is, artificial enzymes. ${ }^{1}$ Recent developments in nanomaterial synthesis and characterization have triggered many scientists to study them as artificial enzymes. ${ }^{1-3}$ A number of nanomaterials, such as $\mathrm{CeO}_{2}{ }^{4} \mathrm{Au}^{5}$ $\mathrm{Fe}_{3} \mathrm{O}_{4}{ }^{6,7}$ carbon nanotubes, ${ }^{8}$ etc., have demonstrated multienzyme-mimic functions of oxidase, ${ }^{9}$ peroxidase, ${ }^{8}$ superoxide dismutase, and phosphatase. ${ }^{10,11}$ Previous studies have shown that the enzymelike activities depend on the size, morphology, composition, and surface coating of nanomaterials, and consequently their activities can be tuned by controlling these parameters. ${ }^{1,2,12}$

Ceria is one of the most studied artificial enzymes among bare nanomaterials with intrinsic enzymatic properties. ${ }^{4}$ The key reason for this is often attributed to its high oxygen storage capacity and high efficiency as an "oxygen buffer". Thus, ceria is able to release and store oxygen when it is treated alternatively under reducing and oxidizing atmospheres, by means of a facile redox $\mathrm{Ce}^{3+} / \mathrm{Ce}^{4+}$ cycle. ${ }^{4}$ Since the pioneering studies by Seal et al. and Perez et al. on nanoceria's functions as artificial enzymes, more investigations have been focused on tuning its enzymelike kinetics and performance. ${ }^{9,13-17}$ Previous studies indicate that ceria with controlled morphologies presents outstanding properties, different from those of conventional ceria particles. ${ }^{9,18,19}$ The exposure of more active facets, which might facilitate the redox cycles, in the case of nanoceria with well-defined shapes must be at the roots of this enhancement of the enzyme-mimic activity. ${ }^{20}$ Doping ceria with other elements, such as other lanthanides or aliovalent cationic metal dopants, can enhance the redox properties of ceria due to an increase in the concentration of oxygen vacancies and oxygen mobility in ceria. ${ }^{18,21,22}$ In particular, $\mathrm{Pr}$ can greatly improve the oxygen storage capacity of ceria because of its redox $\operatorname{Pr}^{3+} / \operatorname{Pr}^{4+}$ couple. ${ }^{21,23,24}$

Though many reports are available on various methodologies, synthesizing enzymatic nanocrystals with controlled size and surface through a single method still remains a challenge. Yang et al. prepared $\mathrm{CeO}_{2}$ nanocubes (NCs) and

Received: May 29, 2021

Accepted: July 26, 2021

Published: August 9, 2021 
nanorods (NRs) exposing different facets via a hydrothermal method. ${ }^{25}$ It was reported that at the same levels of $\mathrm{Ce}^{3+} / \mathrm{Ce}^{4+}$ cations and oxygen vacancies on the surface, $\mathrm{CeO}_{2} \mathrm{NCs}$ with exposed $\{100\}$ facets displayed higher peroxidase but lower superoxide dismutase-mimic activity than $\mathrm{CeO}_{2}$ nanorods with exposed $\{110\}$ facets. ${ }^{25}$ Other researchers have found that in $\mathrm{CO}$ oxidation reaction ceria with defined surface planes exhibit catalytic activities in deceasing order nanorods $>$ nanocubes $>$ octahedral. ${ }^{19,20}$ Our recent work reveals that ceria nanorods without any addition of other metals as the active phase exhibit the highest catalytic activity among the ceria nanocubes, commercial ceria with high and low surface areas, and ceria nanorods for selective oxidation of glycerol in the liquid phase. $^{26}$ Both experimental and theoretical studies have shown that oxygen vacancies are easier to form on $\{110\}$ and $\{100\}$ than on $\{111\}$ facets. ${ }^{19,20}$ Despite the efforts and sometimes controversial results, it is difficult to define a facile synthesis method to control the facets of ceria nanoshapes which allows one to enhance their intrinsic enzymelike activities.

In this study, pure and Pr-doped ceria nanocubes $(5,10$, and $15 \mathrm{~mol} \% \mathrm{Pr}$ ) have been synthesized. Based on previous studies about the effects of surface reconstruction on the intrinsic catalytic activity in $\mathrm{CO}$ oxidation of $\mathrm{Au}$ supported on ceria nanocubes, ${ }^{27}$ a thermal treatment under oxidizing conditions was performed on both ceria nanocubes. Such treatment leads to the transformation of $\{110\}$ surfaces of the nanocubes into a system of $\{111\}$ nanofacets, without significantly changing their overall, cubelike morphology. This study continues to systematically explore the influence of such defects on ceria's artificial enzyme activities, including oxidase, hydroxyl radical scavenger, and phosphatase. Knowing the importance in catalysis of crystal defects on edges and corners of nanoparticles, this study provides us an easy tool in order to control nanofacets of ceria nanocubes with a view to manipulating their enzymatic activities.

\section{EXPERIMENTAL SECTION}

2.1. Synthesis of Pure and Pr-Modified Ceria Nanocubes. $\mathrm{CeO}_{2}$ nanocubes $\left(\mathrm{CeO}_{2} \mathrm{NC}\right)$, together with 5,10 , and $15 \mathrm{~mol} \% \mathrm{Pr}-$ $\mathrm{CeO}_{2}$ nanocubes (namely, $5 \% \mathrm{Pr}-\mathrm{CeO}_{2} \mathrm{NC}, 10 \% \mathrm{Pr}-\mathrm{CeO}_{2} \mathrm{NC}$, and $15 \% \mathrm{Pr}-\mathrm{CeO}_{2} \mathrm{NC}$ ), were synthesized by the same hydrothermal method described in a previous paper. ${ }^{21}$ Ceria NCs with reconstructed nanofacets, namely, $\mathrm{CeO}_{2} \mathrm{NC}-\mathrm{O} 600,5 \% \mathrm{Pr}^{-} \mathrm{CeO}_{2} \mathrm{NC}$ O600, $10 \% \mathrm{Pr}-\mathrm{CeO}_{2} \mathrm{NC}-\mathrm{O} 600$, and $15 \% \mathrm{Pr}-\mathrm{CeO}_{2} \mathrm{NC}-\mathrm{O} 600$, were prepared by oxidizing the $\mathrm{CeO}_{2} \mathrm{NC}, 5 \% \mathrm{Pr}-\mathrm{CeO}_{2} \mathrm{NC}, 10 \% \mathrm{Pr}-$ $\mathrm{CeO}_{2} \mathrm{NC}$, and $15 \% \mathrm{Pr}-\mathrm{CeO}_{2} \mathrm{NC}$ samples in a $60 \mathrm{~mL} \mathrm{~min}^{-1}$ flow of $5 \%$ $\mathrm{O}_{2} / \mathrm{He}$ at $600{ }^{\circ} \mathrm{C}$ for $1 \mathrm{~h}$. Afterward, the samples were cooled down to room temperature under the same oxidizing mixture.

2.2. Characterization of Catalysts. The pure and Pr-doped ceria nanocube samples were characterized by powder X-ray diffraction (XRD), X-ray photoelectron spectroscopy (XPS), inductively coupled plasma-atomic emission spectroscopy (ICP-AES), Raman spectroscopy, and transmission electron microscopy (TEM) techniques. XRD patterns were recorded on a D8 ADVANCE diffractometer of Bruker using $\mathrm{Cu} \mathrm{K} \alpha$ radiation. The intensity data were collected over a $2 \theta$ range of $20-70^{\circ}$. The average crystallite size of all the oxides was estimated by the Scherrer equation using the width of the $\{111\}$ diffraction peak of ceria at $28.6^{\circ}$. Likewise, the lattice parameters of all the ceria nanocubes were calculated using the Bragg equation.

The actual Pr content of the doped nanocubes was analyzed using ICP-AES equipment (Iris Intrepid, Thermal Elemental). The Brunauer-Emmett-Teller (BET) surface areas of the samples were determined by $\mathrm{N}_{2}$ physisorption at $-196{ }^{\circ} \mathrm{C}$ on a Micromeritics ASAP 2020.

XPS measurements were performed on a Kratos Axis Ultra DLD instrument to characterize the surface chemical composition and oxidation state of the samples. The spectra were collected using monochromatized $\mathrm{Al} \mathrm{K} \alpha$ radiation $(1486.6 \mathrm{eV})$, with an $\mathrm{X}$-ray power of $150 \mathrm{~W}$. The spectrometer was operated in the constant analyzer energy mode, with a pass energy of $20 \mathrm{eV}$. The powder samples were pressed to prepare self-supported pellets, which were stuck on a double-sided adhesive conducting polymer tape. Surface charging effects were compensated by making use of the Kratos coaxial neutralization system. The binding energy (BE) scale was calibrated with respect to the $\mathrm{C} 1 \mathrm{~s}$ signal at $284.8 \mathrm{eV}$.

All the samples were characterized by high-resolution transmission electron microscopy (HRTEM) and scanning transmission electron microscopy-high angle annular dark field (STEM-HAADF) using a JEOL 2010-F microscope and an aberration-corrected FEI Titan ${ }^{3}$ Themis 60-300 microscope. HRTEM images were obtained with 0.19 $\mathrm{nm}$ spatial resolution at Scherzer defocus, and STEM-HAADF images were collected by using an electron probe of $0.5 \mathrm{~nm}$ of diameter at a camera length of $8 \mathrm{~cm}$. Additionally, high spatial energy dispersive $\mathrm{X}$ ray spectroscopy (XEDS) maps were acquired using the ChemiSTEM capabilities of a FEI Titan ${ }^{3}$ Themis 60-300 microscope. In this case, a high brightness, subangstrom $(0.07 \mathrm{~nm})$ diameter electron probe was combined with a highly stable stage to record these maps. Element mapping was acquired with a screen current of $200 \mathrm{pA}$ and a pixel dwell time of $170 \mu \mathrm{s}$. This dwell time resulted in a frame acquisition time of approximately $25 \mathrm{~s}$, after which the drift was corrected using cross correlation. An averaging filter was used on the images as provided in the Esprit software.

Raman spectra of the samples were recorded using a confocal dispersive Raman spectrometer (Jasco, model NRS-7200) in backscattering configuration. A $532 \mathrm{~nm} \mathrm{Nd-YAG} \mathrm{laser} \mathrm{operating} \mathrm{at} 5.6$ $\mathrm{mW}$ power was used as an excitation source. The laser beam was focused on the samples by a $100 \times$ microscope objective, with a spot size of about $1 \mu \mathrm{m}$ diameter.

The reducibility of ceria nanocubes was studied by temperatureprogrammed reduction analysis with $\mathrm{H}_{2}\left(\mathrm{H}_{2}-\mathrm{TPR}\right)$. About $150 \mathrm{mg}$ of the powder was oxidized under a $5 \% \mathrm{O}_{2} / \mathrm{He}$ flow $\left(60 \mathrm{~mL} \mathrm{~min}^{-1}\right)$ at $500{ }^{\circ} \mathrm{C}$ for $1 \mathrm{~h}$ and cooled in the same oxidizing flow down to $150{ }^{\circ} \mathrm{C}$. Then, the flow was switched to $\mathrm{He}$ in order to remove adsorbed oxygen species on the surface of the samples and cool down the sample to room temperature. Afterward, the $\mathrm{He}$ flow was replaced by a flow of $5 \% \mathrm{H}_{2} / \mathrm{Ar}$ at room temperature. The $\mathrm{H}_{2}$-TPR experiments were carried out in a $60 \mathrm{~mL} \mathrm{~min}^{-1}$ flow of $5 \% \mathrm{H}_{2} / \mathrm{Ar}$ with a heating rate of $10{ }^{\circ} \mathrm{C} \mathrm{min}^{-1}$ from room temperature to a maximum temperature of $950{ }^{\circ} \mathrm{C}$, keeping the sample at this temperature for $1 \mathrm{~h}$. The reactor effluent gas was passed and analyzed by a Thermostar GSD301T1 mass spectrometer from Pfeiffer Vacuum. The mass/ charge ratio $(\mathrm{m} / \mathrm{z})$ value used to monitor $\mathrm{H}_{2} \mathrm{O}$ formation is 18 during the $\mathrm{H}_{2}$-TPR process.

In order to study the effect of Pr modification and the oxidation treatment at $600{ }^{\circ} \mathrm{C}$ on the optical properties of ceria nanocubes and estimate their energy band gap, UV-vis specular and diffuse reflectance measurements were carried out using an Agilent Cary 5000 UV-vis-NIR double-beam spectrophotometer. The spectra in the $200-2500 \mathrm{~nm}$ range were registered in an integrating sphere. A reference sample $\operatorname{Pr}_{6} \mathrm{O}_{11}$ was also studied by this technique. The resulting diffuse reflectance spectra were transformed into apparent absorption spectra using the Kubelka-Munk function $(F(R))$. The direct and indirect optical band gaps of the materials were determined through the construction of Tauc plots by plotting $(F(R) h \nu)^{n}$ against $(h \nu)$, with $n=2$ or $n=1 / 2$, for direct and indirect transitions, respectively. The optical band gap was obtained by extrapolating the linear part of this plot to the energy axis.

2.3. Artificial Enzyme Catalytic Activities. All the chemicals used in this section were purchased from Sigma-Aldrich (U.S.). The oxidase-like activity of the samples was tested for the oxidation of $3,3^{\prime}, 5,5^{\prime}$-tetramethylbenzidine (TMB). ${ }^{21}$ A TMB solution (0.009 M) was prepared by diluting TMB stock $(0.1 \mathrm{M})$ solution in dimethyl sulfoxide (DMSO) with acetate buffer $(\mathrm{pH}=4.0,0.01 \mathrm{M})$. The TMB solution was then stirred thoroughly to avoid precipitation. The nanoceria suspension $\left(0.1 \mathrm{mg} \mathrm{mL}^{-1}\right)$ was prepared by dispersing ceria nanocubes in Milli $Q$ water after washing and centrifuging the sample 
at $12000 \mathrm{rpm}$ for $10 \mathrm{~min}$ three times. The nanoceria suspension was sonicated for $2 \mathrm{~h}$ before each measurement. The UV-vis absorption spectra of TMB at $652 \mathrm{~nm}$ (Shimadzu UV-2450 spectrophotometer) before and after the addition of nanocubes at $40 \mathrm{~min}$ were obtained. Steady kinetic assays on absorbance change over time were monitored in a time course mode using a SpectraMax M2e microplate reader (Molecular Devices, U.S.), where the concentration of ceria and TMB in solution $(200 \mu \mathrm{L})$ were the same as measured with the UV-vis spectrometer.

The hydroxyl radical scavenging ability was studied by investigating their capability to remove the hydroxyl radicals generated from the Fenton reaction as previously described. ${ }^{18}$ The reaction solution used for the photometric determination contained methyl violet ( $\mathrm{MV}, 2.4$ $\left.\times 10^{-5} \mathrm{M}\right), \mathrm{FeSO}_{4}\left(3 \times 10^{-4} \mathrm{M}\right)$, and $\mathrm{H}_{2} \mathrm{O}_{2}(0.4 \mathrm{M})$ in Tris- $\mathrm{HCl}(0.1$ $\mathrm{M}, \mathrm{pH}=4.4)$ buffer. Then, ceria NCs with final concentration $1.7 \mu \mathrm{g}$ $\mathrm{mL}^{-1}$ were added to the Fenton reaction solution, the mixture was blended for $1 \mathrm{~min}$ at room temperature and followed by the addition of MV and UV-vis absorbance measurements at $584 \mathrm{~nm}$ to quantify the concentration of MV. To eliminate the possible influence of ceria's catalase-like activity, in a comparative experiment $21.1 \mu \mathrm{g} \mathrm{mL}^{-1}$ catalase (Aladdin, China) was added together with $1.7 \mu \mathrm{g} \mathrm{mL}^{-1}$ ceria NCs in a similar manner as above.

The phosphatase-like activity of nanoceria was quantified by measuring their efficiency of hydrolytically cleaving the organophosphorus compound paraoxon into $p$-nitrophenol. ${ }^{10}$ This was regarded as mimicking the natural enzymes like phosphotriesterase in bacteria that was able to break down organophosphorus-based nerve agents. ${ }^{28}$ The paraoxon was first dissolved in acetone as stock solution (2 M). $\mathrm{CeO}_{2} \mathrm{NCs}$ with a final concentration of $5 \mathrm{mg} \mathrm{mL}^{-1}(29 \mathrm{mM})$ were added to paraoxon $(0.05 \mathrm{M})$ in $N$-methylmorpholine (NMM) solution $(0.45 \mathrm{M})$. The mixture was thoroughly stirred and the UVvis spectra and absorbance change over time was measured using a UV-vis spectrometer. The specific absorbance peak of $p$-nitrophenol at $401 \mathrm{~nm}$ was monitored. For comparison, $\mathrm{CeCl}_{3}(29 \mathrm{mM})$ and $\mathrm{Ce}\left(\mathrm{SO}_{4}\right)_{2}(29 \mathrm{mM})$ solutions were also tested for the hydrolysis effect.

\section{RESULTS}

3.1. Surface and Structure Characterization. The lowmagnification TEM or STEM-HAADF images of all pure and Pr-doped ceria are shown in Figure S1. It can be clearly confirmed that all these samples possess a cubic morphology. In addition, the particle sizes of these pure ceria nanocube and Pr-modified ceria nanocube samples are mainly between 5 and $50 \mathrm{~nm}$ (Figure S2). Figure 1 presents high-resolution TEM or STEM-HAADF images of four representative samples $\mathrm{CeO}_{2} \mathrm{NC}, \mathrm{CeO}_{2} \mathrm{NC}-\mathrm{O} 600,10 \% \mathrm{Pr}-\mathrm{CeO}_{2} \mathrm{NC}$, and $10 \% \mathrm{Pr}-$ $\mathrm{CeO}_{2} \mathrm{NCO}-\mathrm{O} 600$. Element mapping of the $10 \%$ Pr-modified ceria nanocubes before and after oxidation in Figure 2 shows that $\operatorname{Pr}$ and Ce distribute homogeneously in the nanocubes and that the Pr concentration is around $10 \mathrm{~mol} \%$.

Furthermore, it was found that after oxidation at $600{ }^{\circ} \mathrm{C}$, the ceria nanocube surfaces are roughened into sawtoothlike structures in both pure and Pr-modified ceria nanocubes when they are looked along the $\{110\}$ zone axis (Figures $1 \mathrm{c}, \mathrm{d}$ and $2 e)$. These zigzag structures, or reconstructed $\{111\}$ nanofacets, appear on both oxidized $\mathrm{CeO}_{2} \mathrm{NC}-\mathrm{O} 600$ and $10 \% \mathrm{Pr}-$ $\mathrm{CeO}_{2} \mathrm{NC}-\mathrm{O} 600$ samples. The contributions of the different exposed surfaces, in percentage, calculated using TEM and STEM-HAADF images, are listed in the table inset of Figure 1. A significant fraction of the $\{100\}$ surfaces, $8 \%$ for $\mathrm{CeO}_{2} \mathrm{NC}$ and $14 \%$ for $10 \% \mathrm{Pr}-\mathrm{CeO}_{2} \mathrm{NC}$, has been converted to $\{110\}$ facets. Nevertheless, as observed in the TEM images, these $\{110\}$ surfaces are, in fact, mainly sawtoothlike $\{111\}$ nanofacets of $1-3 \mathrm{~nm}$ in length. ${ }^{29,30}$ Meanwhile, in the case of the pure ceria, the percentage of $\{111\}$ facets slightly

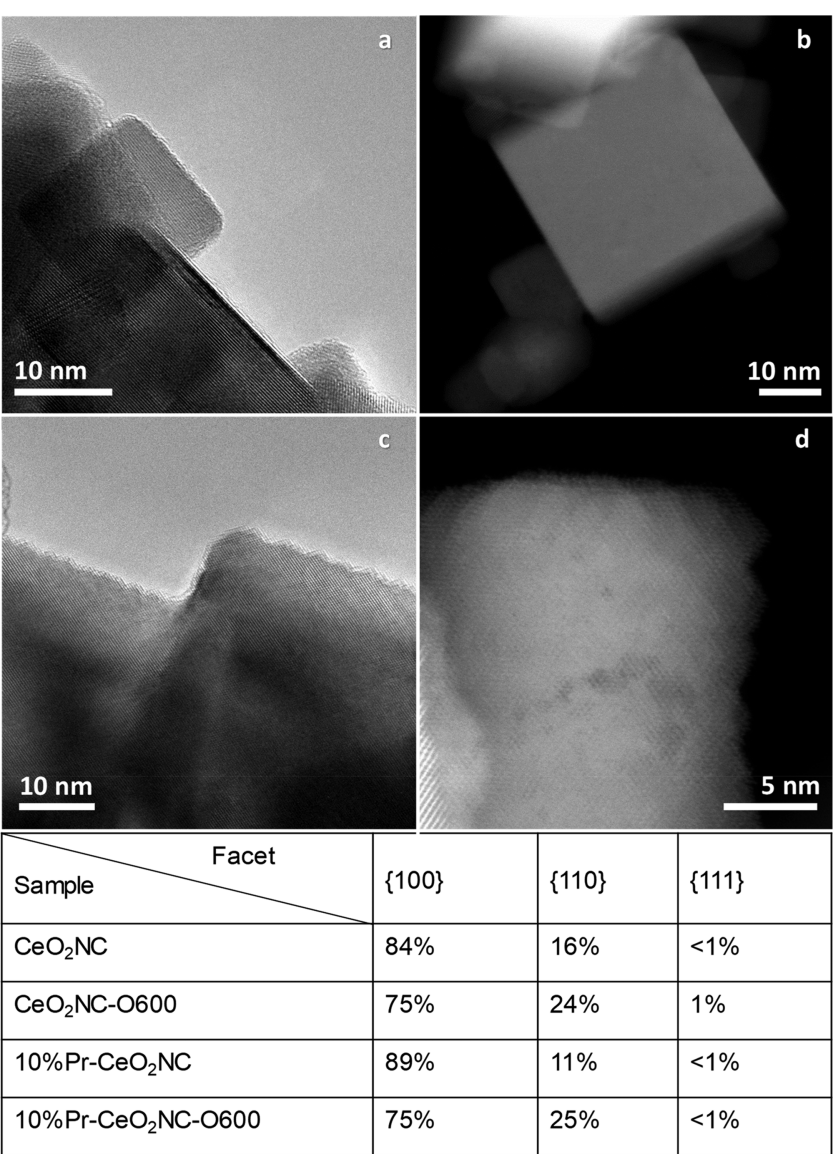

Figure 1. HRTEM images of (a) $\mathrm{CeO}_{2} \mathrm{NC}$ and (c) $\mathrm{CeO}_{2} \mathrm{NC}-\mathrm{O} 600$,

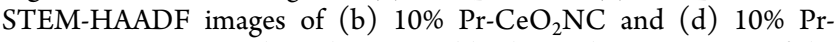
$\mathrm{CeO}_{2} \mathrm{NC}-\mathrm{O} 600$ samples. The inset table shows the percentage of the $\{100\},\{110\}$, and $\{111\}$ facets located at the surfaces, edges, and vertexes of the nanocubes, respectively, measured by TEM and STEM-HAADF techniques.

increase to $1 \%$, corresponding to truncations at the cube corners. For both Pr-doped NCs before and after oxidation, the $\{111\}$ surface maintains less than $1 \%$. In addition, sawtoothlike nanofacets have also been observed over the oxidized $5 \% \mathrm{Pr}-\mathrm{CeO}_{2} \mathrm{NC}-\mathrm{O} 600$ and $15 \% \mathrm{Pr}-\mathrm{CeO}_{2} \mathrm{NC}-\mathrm{O} 600$ samples (Figure S3). Figure S4 shows the element maps of $\mathrm{Ce}$ and $\mathrm{Pr}$ of $5 \% \mathrm{Pr}-\mathrm{CeO}_{2} \mathrm{NC}$ and $15 \% \mathrm{Pr}-\mathrm{CeO}_{2} \mathrm{NC}$ before and after oxidation at $600{ }^{\circ} \mathrm{C}$, indicating that $\operatorname{Pr}$ distributes homogeneously in ceria nanocubes. The Pr concentrations in these samples are similar to their nominal values.

The structural, textural, and surface properties of pure and Pr-doped ceria nanocubes before and after oxidation at $600{ }^{\circ} \mathrm{C}$ were also characterized by XRD, $\mathrm{N}_{2}$ physisorption, and XPS. Figure S5 in the Supporting Information shows XRD patterns of the samples before and after oxidation at $600{ }^{\circ} \mathrm{C}$, confirming the expected fluorite structure of ceria. The incorporation of $\mathrm{Pr}$ in ceria does not cause any change of lattice parameter, which is maintained at $5.4 \AA$ for the samples (Table 1 and Table S1). This can be attributed to the almost identical radius of $\mathrm{Pr}^{4+}$ (96 pm) and $\mathrm{Ce}^{4+}(97 \mathrm{pm})$ cations.

The average particle size was calculated from TEM and XRD data, as shown in Table 1 . In the case of $\mathrm{CeO}_{2} \mathrm{NC}$, it increases from 22 to $31 \mathrm{~nm}$ after oxidation at $600{ }^{\circ} \mathrm{C}$ and from 27 to 37 $\mathrm{nm}$ in $10 \% \mathrm{Pr}-\mathrm{CeO}_{2} \mathrm{NC}$, according to TEM results. The average particle size of the nanocubes calculated by XRD data is quite close to those obtained by TEM data. The increase of 

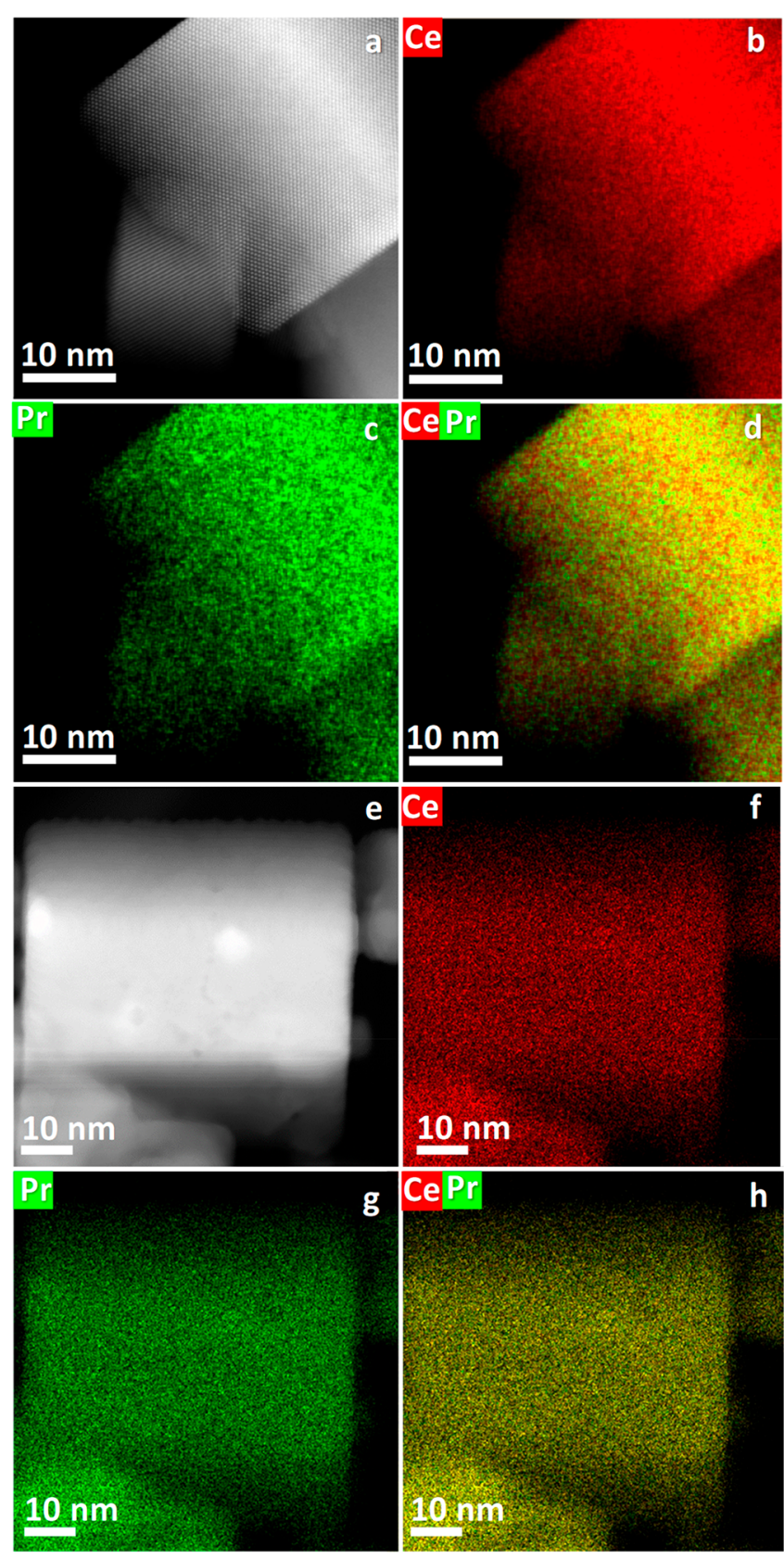

Figure 2. STEM-HAADF images and XEDS element maps of $\mathrm{Ce}, \mathrm{Pr}$ and $\mathrm{Ce}-\mathrm{Pr}$ of $(\mathrm{a}-\mathrm{d}) 10 \% \mathrm{Pr}-\mathrm{CeO}_{2} \mathrm{NC}$ and $(\mathrm{e}-\mathrm{h}) 10 \% \mathrm{Pr}-\mathrm{CeO}_{2} \mathrm{NC}-$ O600. particle size after oxidation at $600{ }^{\circ} \mathrm{C}$ is possibly caused by the partial agglomeration induced by the thermal treatment. This hypothesis is confirmed by $\mathrm{N}_{2}$ physisorption results. In fact, BET specific surface areas of the samples decreased from 38 to $18 \mathrm{~m}^{2} \mathrm{~g}^{-1}$ for $\mathrm{CeO}_{2} \mathrm{NC}$ and from 25 to $20 \mathrm{~m}^{2} \mathrm{~g}^{-1}$ for $10 \% \mathrm{Pr}$ $\mathrm{CeO}_{2} \mathrm{NC}$. The surface areas calculated using TEM data for a nontruncated cubic model, which takes into account the cube length distribution in both samples, provide estimates of the surface area very similar to $\mathrm{N}_{2}$ physisorption results and show the same trend with respect to the effect of the oxidizing treatment. The BET surface areas of $5 \% \mathrm{Pr}-\mathrm{CeO}_{2} \mathrm{NC}$ and $15 \%$ Pr-CeO ${ }_{2} \mathrm{NC}$ samples (Table S1) are 26 and $23 \mathrm{~m}^{2} \mathrm{~g}^{-1}$, which are very similar to that of $\mathrm{Pr}$-doped ceria nanocubes with $10 \%$ Pr.

XPS spectra of the four representative ceria samples are displayed in Figure S6 of the Supporting Information. Ce 3d peak shapes of the four samples are quite similar, and only very small amount of $\mathrm{Ce}^{3+}$ were present on the surface of nanocubes, in agreement with previous reports on little $\mathrm{Ce}^{3+}$ percentage in nanoceria. ${ }^{18,21,31}$ This was especially true in the case of $10 \% \mathrm{Pr}-\mathrm{CeO}_{2} \mathrm{NC}-\mathrm{O} 600$ sample, in which no $\mathrm{Ce}^{3+}$ is detected. Concerning $\mathrm{Pr}$ oxidation state, $10 \% \mathrm{Pr}-\mathrm{CeO}_{2} \mathrm{NC}$ sample showed $100 \%$ of $\operatorname{Pr}^{3+}$, whereas after oxidizing at 600 ${ }^{\circ} \mathrm{C}$, a small amount of $\mathrm{Pr}^{4+}$ could be detected on the surface. Table 1 lists the bulk and surface composition of the Prmodified samples analyzed by ICP and XPS. In agreement with the XEDS analysis before and after thermal treatment, the concentration of Pr in the bulk and surface is around $10 \mathrm{~mol} \%$. All these data suggest that $\operatorname{Pr}$ distributes homogeneously in ceria nanocubes, both before and after oxidation at $600{ }^{\circ} \mathrm{C}$. Table S1 also shows the ICP and XPS results of 5\% and $15 \%$ Pr-doped ceria nanocubes. Their Pr concentrations according to ICP results are very close to the nominal values. However, the $\mathrm{Pr}$ concentrations on the surface of these two samples are 11.9 and $25.1 \%$, which are higher than theoretical values.

3.2. Optical Properties. UV-vis specular and diffuse reflectance measurements were carried out, and the band gaps of four representative samples could therefore be estimated. A strong absorption around $320 \mathrm{~nm}$ was observed on all the samples in Figure 3, which could be assigned to the charge transfer transition from $\mathrm{O} 2 \mathrm{p}$ to $\mathrm{Ce} 4 \mathrm{f}^{32}$ In Pr-doped samples, a broad absorption peak appears between 400 and $600 \mathrm{~nm}$ which is absent in pure $\mathrm{CeO}_{2}$ nanocubes. The appearance of this peak might be related to the interfacial polaron effect emerging from electron-phonon interaction ${ }^{33}$ and increased oxygen vacancies when some $\mathrm{Ce}^{4+}$ ions in the lattice are replaced by $\mathrm{Pr}^{3+}$ ions. ${ }^{34}$ The latter can be represented by Kroger-Vink notation (eq 1) where $\mathrm{Ce}_{\mathrm{Ce}}{ }^{x}$ is $\mathrm{Ce}^{4+}$ in the

Table 1. Physicochemical Properties of the Samples

\begin{tabular}{|c|c|c|c|c|c|c|c|c|c|c|}
\hline \multirow[b]{2}{*}{ sample } & \multirow[b]{2}{*}{$\begin{array}{c}\text { BET surface } \\
\text { areas }\left(\mathrm{m}^{2} \mathrm{~g}^{-1}\right)\end{array}$} & \multirow[b]{2}{*}{$\begin{array}{l}\text { calculated surface } \\
\text { area }\left(\mathrm{m}^{2} \mathrm{~g}^{-1}\right)^{a}\end{array}$} & \multicolumn{2}{|c|}{$\begin{array}{c}\text { composition } \\
\text { by ICP } \\
(\operatorname{mol} \%)\end{array}$} & \multicolumn{2}{|c|}{$\begin{array}{l}\text { composition } \\
\text { by XPS } \\
(\mathrm{mol} \%)\end{array}$} & \multirow{2}{*}{$\begin{array}{l}\mathrm{Ce}^{3+} \text { in total } \\
\text { amount of } \mathrm{Ce} \\
(\%)^{b}\end{array}$} & \multirow{2}{*}{$\begin{array}{l}\text { average } \\
\text { particle size } \\
(\mathrm{nm})^{a}\end{array}$} & \multirow{2}{*}{$\begin{array}{c}\tau \\
\text { Scherrer } \\
(\mathrm{nm})^{c}\end{array}$} & \multirow{2}{*}{$\begin{array}{l}\text { lattice } \\
\text { parameter } \\
(\AA)^{c}\end{array}$} \\
\hline & & & $\mathrm{Ce}$ & $\operatorname{Pr}$ & $\mathrm{Ce}$ & $\operatorname{Pr}$ & & & & \\
\hline $\mathrm{CeO}_{2} \mathrm{NC}$ & 38 & 33 & & & & & 9 & 22 & 21 & 5.4 \\
\hline $\mathrm{CeO}_{2} \mathrm{NC}-\mathrm{O} 600$ & 18 & 19 & & & & & 7 & 31 & 37 & 5.4 \\
\hline $10 \% \mathrm{Pr}-\mathrm{CeO}_{2} \mathrm{NC}$ & 25 & 23 & 90.3 & 9.7 & 90.6 & 9.4 & 2 & 27 & 29 & 5.4 \\
\hline $10 \% \mathrm{Pr}-\mathrm{CeO}_{2} \mathrm{NC}-\mathrm{O} 600$ & 20 & 18 & & & 89.2 & 10.8 & 0 & 37 & 41 & 5.4 \\
\hline
\end{tabular}

${ }^{a}$ Calculated from the particle size distribution, including around 100 nanoparticles, obtained by TEM. ${ }^{b}$ Calculated using XPS data. ${ }^{c}$ Calculated using XRD data. 


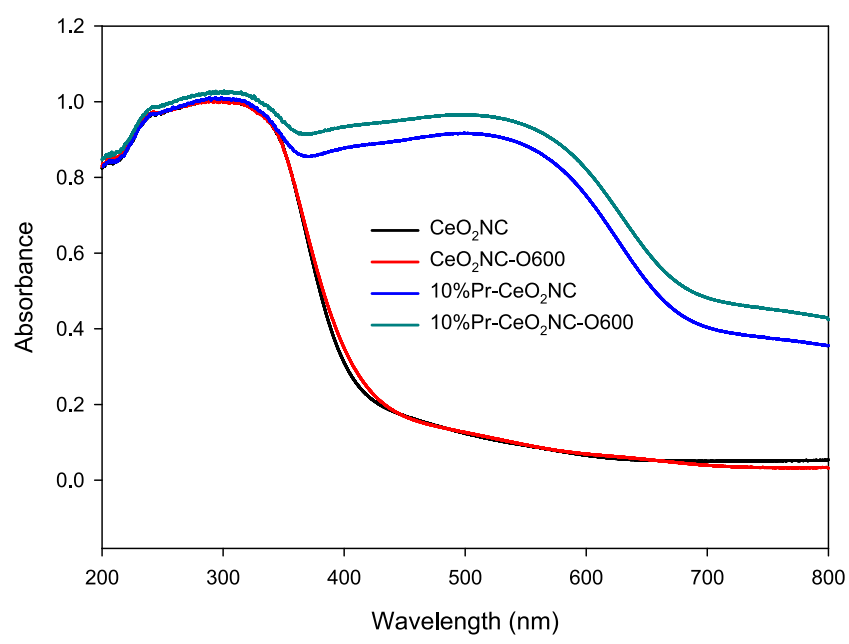

Figure 3. UV-vis absorption spectra of the ceria nanocube samples.

lattice, $\mathrm{VO}^{\bullet \bullet}$ is the oxygen vacancy, and $\mathrm{O}_{\mathrm{O}}$ is the $\mathrm{O}^{2-}$ ion on the respective lattice site.

$$
\mathrm{Pr}_{2} \mathrm{O}_{3}+2 \mathrm{Ce}_{\mathrm{Ce}}^{x} \rightarrow 2 \mathrm{Ce}_{\mathrm{Ce}}^{\prime}+2 \mathrm{VO}^{\bullet \bullet}+2 \mathrm{O}_{\mathrm{O}}^{x}+\frac{1}{2} \mathrm{O}_{2}+2 \mathrm{Pr}_{\mathrm{Ce}}^{\prime}
$$

From the UV diffuse reflectance results, the indirect and direct band gap energies of the studied materials were determined by using the Kubelka-Munk function as shown in Figure S7 in the Supporting Information. In Table 2, both indirect and

Table 2. Indirect and Direct Band Gaps of All the Samples and Raman $I_{\mathrm{D}} / I_{\mathrm{F} 2 \mathrm{~g}}$ Ratios of Pr-Doped Ceria Nanocubes

\begin{tabular}{lccc}
\multicolumn{1}{c}{ catalysts } & indirect $E_{\mathrm{g}}(\mathrm{eV})$ & direct $E_{\mathrm{g}}(\mathrm{eV})$ & $\begin{array}{c}\text { Raman } \\
I_{\mathrm{D}} / I_{\mathrm{F} 2 \mathrm{~g}}\end{array}$ \\
$\mathrm{CeO}_{2} \mathrm{NC}$ & $3.17 \pm 0.05$ & $3.50 \pm 0.05$ & \\
$\mathrm{CeO}_{2} \mathrm{NC}-\mathrm{O} 600$ & $3.19 \pm 0.06$ & $3.49 \pm 0.05$ & \\
$10 \% \mathrm{Pr}^{-\mathrm{CeO}_{2} \mathrm{NC}}$ & $2.95 \pm 0.03$ & $3.53 \pm 0.04$ & 0.25 \\
$10 \% \mathrm{Pr}_{-}-\mathrm{CeO}_{2} \mathrm{NC}-\mathrm{O} 600$ & $2.86 \pm 0.06$ & $3.51 \pm 0.05$ & 0.38 \\
\hline
\end{tabular}

direct band gap values are obtained following the procedure described in the Experimental Section. As it can be seen, the fundamental band gap of the studied materials can be assigned in all cases to the indirect one, since it is smaller than the direct one. $^{35}$

As shown in Table 2, the direct band gap energies of all the samples are around $3.50 \mathrm{eV}$, within the $3.2-3.6 \mathrm{eV}^{\text {range }} \mathrm{e}^{36-38}$ that was previously reported for ceria nanocrystals in the literature. This value is notably higher than that of bulk $\mathrm{CeO}_{2}$ nanocrystals $(3.15 \mathrm{eV})$, probably mainly because of the quantum confinement effect. ${ }^{36}$ The value of direct band gap energies does not seem to be affected neither by the oxidation treatment at $600{ }^{\circ} \mathrm{C}$ nor by the addition of $\operatorname{Pr}$ to the ceria nanocubes.

The indirect band gap energies are systematically lower than direct ones in an amount depending on the sample. The indirect band gap of pure ceria nanocubes with or without oxidation at $600{ }^{\circ} \mathrm{C}$ is lower than the direct band gap by around $0.3 \mathrm{eV}$. The indirect band gap values decrease from 3.2 to $2.9 \mathrm{eV}$, when $\mathrm{Pr}$ is doped in the ceria nanocubes, which is in accordance with the values of the indirect band gap (2.9-3.3 $\mathrm{eV}$ ) in the literature. ${ }^{36-38}$ Furthermore, the indirect band gap energy is even lower when the $10 \% \mathrm{Pr}-\mathrm{CeO}_{2} \mathrm{NC}$ sample is oxidized at $600{ }^{\circ} \mathrm{C}$. It has been reported that the indirect band gap may be due to the band shifting from crystal structure truncation and atomic structure distortion on the nanoparticle surface. $^{39,40}$ For the ceria nanocubes in this work, if the indirect band gap results are mainly from the surface distortion and thus higher lattice vibration, the smaller indirect band gap may suggest that the Pr doping and the subsequent thermal treatment can effectively help the indirect electron transitions from the valence band (VB) to the conduction band (CB).

Raman spectroscopy is frequently used to directly characterize the oxygen vacancies and defects in ceria. Figure 4 depicts

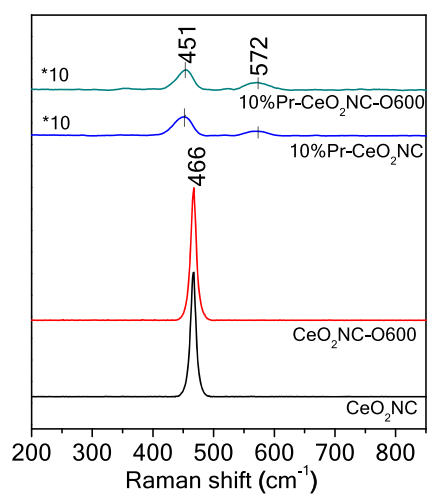

Figure 4. Raman spectra of the ceria nanocube samples.

Raman spectra of four representative ceria nanocube samples. Raman band observed at $466 \mathrm{~cm}^{-1}$ in both $\mathrm{CeO}_{2} \mathrm{NC}$ and $\mathrm{CeO}_{2} \mathrm{NC}$-O600 samples is reported to be attributed to the $\mathrm{F}_{2 g}$ symmetrical stretching vibration mode of $\mathrm{CeO}_{2}$ in the symmetrical breathing mode of the $\mathrm{Ce}-\mathrm{O} 8$ vibration unit. ${ }^{34}$

When the ceria nanocubes are modified with Pr before and after oxidation pretreatment, a clear shift of the $\mathrm{F}_{2 g}$ band to lower frequencies of $451 \mathrm{~cm}^{-1}$ is observed. This shift may be attributed to two consequences of Pr modification. The first one is the increased oxygen vacancies $\left(\mathrm{VO}^{\bullet \bullet}\right)$ when every two $\mathrm{Pr}^{3+}$ cations replace a $\mathrm{Ce}^{4+}$ cation. The second one is the dilation or contraction of the lattice. ${ }^{41}$ The changes in the $\mathrm{Ce}-$ $\mathrm{O}$ and $\mathrm{Pr}-\mathrm{O}$ bond length and atomic geometry induce the shifting of the $\mathrm{F}_{2 g}$ band. Furthermore, full width half-maximum (fwhm) values have been determined to be 10 and $11 \mathrm{~cm}^{-1}$ for $\mathrm{CeO}_{2} \mathrm{NC}$ and $\mathrm{CeO}_{2} \mathrm{NC}-\mathrm{O} 600$ samples, while fwhm values for Pr-doped samples have been found to be 35 and $30 \mathrm{~cm}^{-1}$ for samples without and with oxidation pretreatment, respectively. The $\mathrm{F}_{2 g}$ band becomes wider than that of pure $\mathrm{CeO}_{2} \mathrm{NC}$, probably due to the generated $\mathrm{VO}^{\bullet \bullet}$ and lattice strain.

Other than the shift of the $\mathrm{F}_{2 g}$ band, a pronounced $\mathrm{D}$ band invariably appears at $572 \mathrm{~cm}^{-1}$ for both Pr-modified $\mathrm{CeO}_{2} \mathrm{NCs}$. This $\mathrm{D}$ band can be assigned to oxygen vacancies and defect sites. ${ }^{42-44}$ If the intensity of the $\mathrm{F}_{2 g}$ band $\left(I_{\mathrm{F}_{2 g}}\right)$ is used as an internal standard, the relative intensity ratio of $I_{\mathrm{D}} / I_{\mathrm{F}_{2 g}}$ can be a good indicator for the amount of bulk oxygen vacancies, where $I_{\mathrm{D}}$ is the intensity of the $\mathrm{D}$ band. ${ }^{41,43,45}$ As shown in Table 2, the $I_{\mathrm{D}} / I_{\mathrm{F}_{2 g}}$ value of $10 \% \mathrm{Pr}-\mathrm{CeO}_{2} \mathrm{NC}-\mathrm{O} 600$ is higher than that of the unoxidized sample, suggesting that the $600{ }^{\circ} \mathrm{C}$ treatment may have caused an increase of $\mathrm{VO}^{\circ}$ and defect sites in the Prdoped nanocubes. It is also worth noting that Raman spectra of the measured samples may vary depending on the excitation wavelength and the sample absorbance capability. ${ }^{46}$ For $\mathrm{CeO}_{2} \mathrm{NC}$ and $\mathrm{CeO}_{2} \mathrm{NC}-\mathrm{O} 600$, they have no absorbance at $532 \mathrm{~nm}$, which is the excitation wavelength for Raman spectra 
from UV-vis spectra in Figure 3. Therefore, their Raman spectra largely represent the signal from the bulk structure. On the contrary, $10 \% \mathrm{Pr}-\mathrm{CeO}_{2} \mathrm{NC}$ and $10 \% \mathrm{Pr}-\mathrm{CeO}_{2} \mathrm{NC}-\mathrm{O} 600$ can strongly absorb the $532 \mathrm{~nm}$ excitation light, which means that their Raman signals are mainly from the nanocube surface. Therefore, the observed values of the intensity ratios clearly confirm an increase of the concentration of surface defects after the thermal treatment, in good agreement with the TEM/ STEM results.

3.3. Redox Properties. The redox properties of the four representative samples were characterized using $\mathrm{H}_{2}$-TPR experiments. Figure 5 depicts the $\mathrm{H}_{2} \mathrm{O}$ formation during $\mathrm{H}_{2}$ -

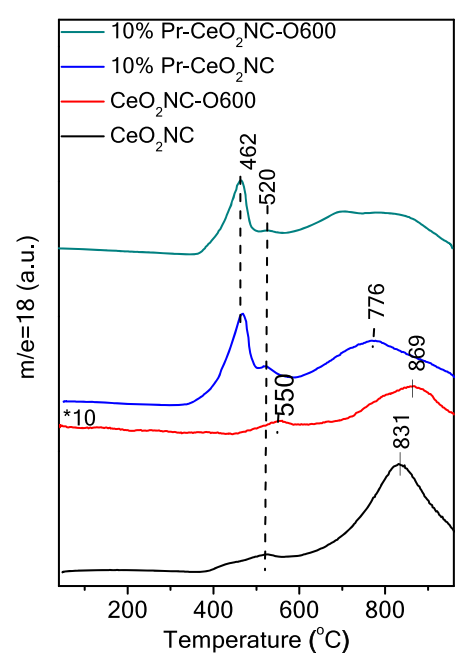

Figure 5. TPR profiles of the different ceria nanocube samples. The $m / z=18$ signal in $\mathrm{H}_{2}$-TPR corresponds to $\mathrm{H}_{2} \mathrm{O}$ evolution.

TPR, in which oxygen is taken out from the surface or the bulk of the samples. Two reduction peaks at 520 and $831{ }^{\circ} \mathrm{C}$, which can be attributed to the reduction of the surface and the bulk of ceria, are observed in the $\mathrm{CeO}_{2} \mathrm{NC}$ sample. The oxidation at $600{ }^{\circ} \mathrm{C}$ of the pure ceria nanocube sample leads to a slight shift of both peaks to higher reduction temperatures, 550 and 869 ${ }^{\circ} \mathrm{C}$. However, three reduction events, at 462,520 , and $776{ }^{\circ} \mathrm{C}$, are observed in the $10 \% \mathrm{Pr}-\mathrm{CeO}_{2} \mathrm{NC}$ sample. As previously reported, the $\mathrm{Pr}$ incorporation in NCs increases the reducibility, shifting the reduction peaks to lower temperatures. ${ }^{21}$ After oxidation at $600{ }^{\circ} \mathrm{C}$, the TPR profile of the $10 \%$ $\mathrm{Pr}-\mathrm{CeO}_{2} \mathrm{NC}-\mathrm{O} 600$ sample is quite similar to that of the original sample, with a broader reduction peak at lower temperatures. This shoulder shifting to a lower temperature suggests that the treated $10 \% \mathrm{Pr}-\mathrm{CeO}_{2} \mathrm{NC}-\mathrm{O} 600$ is to some extent easier to be reduced than the untreated one.

3.4. Biomimetic Enzyme Activities. The biomimetic enzyme activities of nanoceria have been studied previously with wide application in biomedicine and environmental protection. ${ }^{1,4}$ Depending on the aqueous solution conditions, nanoceria exhibits versatile performances, such as mimicking oxidase, superoxide dismutase, peroxidase, hydroxyl radical scavenger, phosphatase, etc. ${ }^{1,47}$ In order to investigate the effects of Pr modification and thermal treatment on $\mathrm{CeO}_{2} \mathrm{NCs}$, three distinctive and characteristic capabilities, mimicking oxidase, hydroxyl radical scavenger, and phosphatase, which represent the oxidizing, reducing, and hydrolytic properties, respectively, have been evaluated in this work.
The oxidase-like activity was examined by the TMB oxidation experiment. ${ }^{21}$ Figure $6 a$ shows that upon the addition of ceria nanocubes, the colorless TMB solution quickly turns blue, which is attributed to the generation of blue-colored oxidized TMB with absorbance at $652 \mathrm{~nm}$. Figure $6 \mathrm{~b}$ compares the $652 \mathrm{~nm}$ absorbance change for the eight types of nanocubes. On one hand, Pr-modification slightly improves the oxidizing efficiency. On the other hand, for pure and Prdoped ceria NCs, independent of the Pr concentrations in ceria nanocubes, after oxidation at $600{ }^{\circ} \mathrm{C}$ their performance is largely enhanced, with the oxidization yield increasing more than $50 \%$. Considering the activity per unit surface area of four representative samples, the differences are even more remarkable, as shown in Figure S8a.

The antioxidant activity of the ceria samples was also investigated by measuring their capability to eliminate hydroxyl radicals as described previously. ${ }^{18}$ Figure $6 \mathrm{c}$ uses absorbance of MV $\left(2.4 \times 10^{-5} \mathrm{M}\right)$ with a purple color at $584 \mathrm{~nm}$ as an indicator which can be oxidized by the hydroxyl radicals generated by Fenton reagents, $\mathrm{Fe}^{2+}$ and $\mathrm{H}_{2} \mathrm{O}_{2}$, in vitro. After addition of the Fenton reagent $\left(3 \times 10^{-4} \mathrm{M} \mathrm{FeSO}_{4}\right.$ and $0.4 \mathrm{M}$ $\mathrm{H}_{2} \mathrm{O}_{2}$ ), MV was oxidized to colorless ox-MV, a process which can clearly be inhibited by adding $10 \% \mathrm{Pr}-\mathrm{CeO}_{2} \mathrm{NC}(1.7 \mu \mathrm{g}$ $\left.\mathrm{mL}^{-1}\right)$. The absorbance difference $\Delta A$ of $\mathrm{MV}+$ Fenton solution without and with adding NCs is linearly related to the amount of eliminated radicals, which suggests a direct relationship between the scavenging activity and reducibility of nanoceria. The $\Delta A$ in the presence of the eight NC samples in Figure $6 \mathrm{~d}$ shows that the oxidized NCs, again, are more active in removing radicals than the untreated ones. Similar results are obtained by comparing $\Delta A$ normalized by the surface area of nanocubes (Figure S8b). This is in accordance to the enhanced oxidase activity in Figure 6a,b. It is worth mentioning that the scavenging ability of $\mathrm{Pr}$-doped $\mathrm{CeO}_{2} \mathrm{NC}$ is not as good as that of $\mathrm{CeO}_{2} \mathrm{NC}$, and the same tendency is observed for the oxidized samples. This means that although Pr-doping can enhance the oxidizing capacity of $\mathrm{CeO}_{2} \mathrm{NC}$, in the meantime, it weakens the reducing capacity of ceria which is contrary to our previous studies on La-doped $\mathrm{CeO}_{2}$ nanocubes. ${ }^{18}$ Furthermore, considering the possible influence of catalase-like activity of nanoceria that was previously reported, ${ }^{48}$ a comparative MV experiment was carried out in which $21.1 \mu \mathrm{g} \mathrm{mL}^{-1}(\sim 4.2$ unit) natural catalase (CAT) was added together with $\mathrm{CeO}_{2} \mathrm{NC}$. The results in Figure S9 show that it induced an absorbance change of less than 5\% compared with data without CAT. Therefore, it is believed that the impact of catalase-like activity, if any, of nanoceria would be negligible in the MV experiment.

Other than the calatase-like activity of nanoceria, the possible reaction between $\mathrm{H}_{2} \mathrm{O}_{2}$ and $\mathrm{CeO}_{2}$ can also partly contribute to the enhanced hydroxyl radical scavenging ability of thermally treated ceria samples. Recent studies have suggested that ceria nanoparticles can be directly used to detect $\mathrm{H}_{2} \mathrm{O}_{2}$ and that their sensibility toward $\mathrm{H}_{2} \mathrm{O}_{2}$ is sizedependent. $^{49-51}$ For ceria nanoparticles of $<40 \mathrm{~nm}$ size, a partial reversible phase transformation can occur at the surface in the presence of highly concentrated $\mathrm{H}_{2} \mathrm{O}_{2}$ aqueous solution. The larger the particle size, the less reactivity between ceria and $\mathrm{H}_{2} \mathrm{O}_{2}$. In this study, Table 1 shows that the average particle sizes, for both $\mathrm{CeO}_{2}$ and $10 \% \mathrm{Pr}-\mathrm{CeO}_{2} \mathrm{NC}$, increased from 22 and $27 \mathrm{~nm}$ to 31 and $37 \mathrm{~nm}$, respectively. As it can be seen in Figure S2, the percentage of nanocubes bigger than 40 $\mathrm{nm}$ for $\mathrm{CeO}_{2} \mathrm{NC}$ and $10 \% \mathrm{Pr}-\mathrm{CeO}_{2} \mathrm{NC}$ is very small (around 1 and $9 \%$ ). After oxidation at $600{ }^{\circ} \mathrm{C}$, the percentage of 

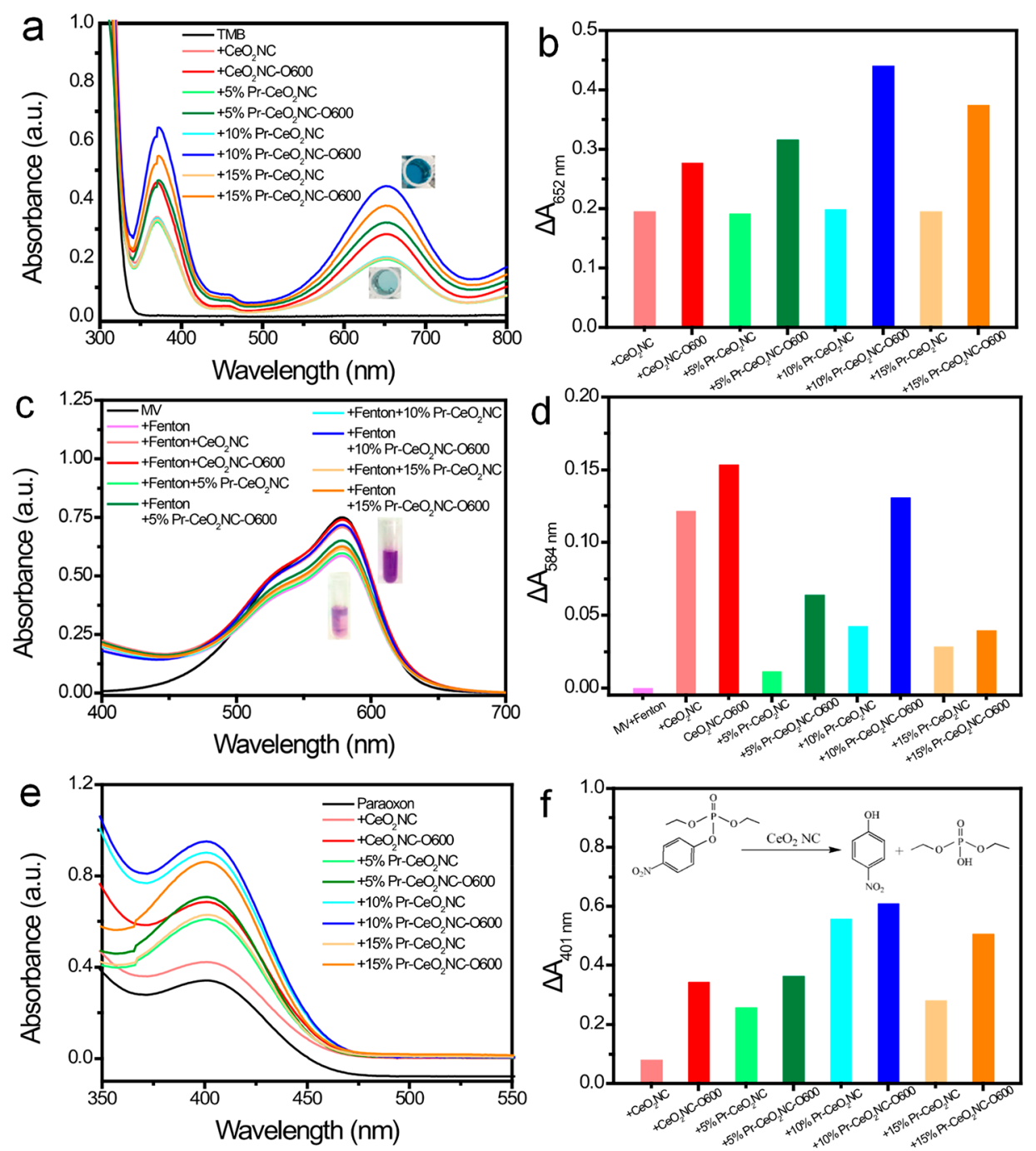

Figure 6. Activities of $\mathrm{CeO}_{2} \mathrm{NC}, \mathrm{CeO}_{2} \mathrm{NC}-\mathrm{O} 600,5 \% \mathrm{Pr}-\mathrm{CeO}_{2} \mathrm{NC}, 5 \% \mathrm{Pr}-\mathrm{CeO}_{2} \mathrm{NC}-\mathrm{O} 600,10 \%$ Pr-CeO ${ }_{2} \mathrm{NC}, 10 \%$ Pr-CeO 2 NC-O600, $15 \%$ Pr$\mathrm{CeO}_{2} \mathrm{NC}$, and $15 \% \mathrm{Pr}-\mathrm{CeO}_{2} \mathrm{NC}-\mathrm{O} 600$ as enzyme-mimics of oxidase, hydroxyl radical scavenger, and phosphatase. (a) UV-vis spectra of TMB $(0.009 \mathrm{M})$ after mixing with ceria $\left(0.1 \mathrm{mg} \mathrm{mL}^{-1}\right)$ samples in $\mathrm{pH} 4.0$ buffer. Inset photos show the color change when TMB is oxidized. (b) Comparison of the performance of the eight ceria samples in TMB oxidation; (c) UV-vis spectra of MV $\left(2.4 \times 10^{-5} \mathrm{M}\right)$ after mixing with Fenton reagent $\left(\mathrm{FeSO}_{4}\right.$ and $\left.\mathrm{H}_{2} \mathrm{O}_{2}\right)$, with and without the presence of different ceria $\left(1.7 \mu \mathrm{g} \mathrm{mL}^{-1}\right)$ samples. Inset photos show the color recovery as the Fenton-generated hydroxyl radicals are removed. (d) Comparison of the performance of the eight ceria samples in eliminating hydroxyl radicals; (e) UV-vis spectra of paraoxon $(0.05 \mathrm{M})$ in the presence of $5 \mathrm{mg} \mathrm{mL}^{-1}(29 \mathrm{mM})$ ceria samples. The absorbance peak at $401 \mathrm{~nm}$ is from the hydrolysis product $p$-nitrophenol. (f) Comparison of the performance of the eight ceria samples in hydrolyzing paraoxon, catalytic reaction shown in the inset.

nanocubes bigger than $40 \mathrm{~nm}$ of these two samples increases to 11 and $20 \%$, respectively. This suggests that the size increase after oxidation of ceria nanocubes would not result in the dramatic change of reaction between $\mathrm{H}_{2} \mathrm{O}_{2}$ and ceria nanocubes. Thus, with combination of catalase results, the antioxidant activity on ceria nanocube samples and enhancement of antioxidant activity after oxidation at $600{ }^{\circ} \mathrm{C}$ cannot be only due to direct reaction between $\mathrm{H}_{2} \mathrm{O}_{2}$ and ceria nanocubes.

Finally, the phosphatase activity of the ceria nanocubes was measured by the paraoxon degradation experiment. Phosphatase, or phosphotriesterase (PTE), is one of the key enzymes in the cell signal transduction system. Bacteria uses it to break down organophosphorus compounds in residue of pesticides or chemical warfare agents. ${ }^{28}$ Figure $6 \mathrm{e}$ illustrates the UV-vis spectra of paraoxon $(0.05 \mathrm{M})$ with and without the presence of $5 \mathrm{mg} \mathrm{mL} \mathrm{mL}^{-1}(\sim 29 \mathrm{mM})$ ceria nanocubes. The specific absorbance peak of degraded product $p$-nitrophenol at 401 $\mathrm{nm}$ shows that ceria NCs can catalyze the hydrolysis of paraoxon in NMM solution, in agreement with previously reported results for vacancy-enhanced ceria nanoparticles. ${ }^{10}$ It can be seen in Figure $6 f$ that under the same conditions, the hydrolysis efficiency of four representative nanocubes are in the order $10 \%$ Pr-CeO ${ }_{2} \mathrm{NC}-\mathrm{O} 600>10 \% \mathrm{Pr}-\mathrm{CeO}_{2} \mathrm{NC}>$ $\mathrm{CeO}_{2} \mathrm{NC}-\mathrm{O} 600>\mathrm{CeO}_{2} \mathrm{NC}$. In addition, the oxidized samples are better than the original samples, $\sim 4$-fold for $\mathrm{CeO}_{2} \mathrm{NC}$ and $11 \%$ higher for $10 \% \mathrm{Pr}-\mathrm{CeO}_{2} \mathrm{NC}$. The same tendency occurs when the absorbance was normalized by the surface area of the samples, as in Figure S8c. For 5\% $\mathrm{Pr}-\mathrm{CeO}_{2} \mathrm{NC}$ and $15 \% \mathrm{Pr}-$ $\mathrm{CeO}_{2} \mathrm{NC}$ catalysts, the oxidized Pr-doped ceria nanocubes present higher hydrolysis efficiency than the original ones (Figure 6f).

It is noted that the hydrolysis efficiency above is not as high as previously reported by Mugesh et al., who managed to 
hydrolyze $>80 \%$ paraoxon in similar conditions. ${ }^{10}$ This may be due to the different synthetic conditions for their vacancyenhanced ceria nanoparticles. In order to figure out the possible role of $\mathrm{Ce}^{3+}$ in the hydrolysis reaction, as also suggested previously, ${ }^{10,52} 29 \mathrm{mM} \mathrm{Ce}^{3+}$ and $\mathrm{Ce}^{4+}$ were added to paraoxon in NMM solution, respectively. However, hydrolysis efficiencies of $\mathrm{Ce}^{3+}$ or $\mathrm{Ce}^{4+}$ are very low (Figure S10), even if at much higher $\mathrm{Ce}^{3+}$ concentration than their study. ${ }^{10}$ It suggests that isolated $\mathrm{Ce}^{3+}$ ions in solution present poor catalytic activity to degrade paraoxon, and the phosphatase activity of ceria nanocubes may be not solely or directly associated with the $\mathrm{Ce}^{3+}$ ions in the aqueous solution. The degradation of organophosphorus occurs on the surface of ceria nanocubes. The $\mathrm{Ce}^{3+}$ and $\operatorname{Pr}^{3+}$ species on the surface of these catalysts play an important role in this artificial enzymatic reaction. The mechanism will be discussed later.

\section{DISCUSSION}

Taken together, the above-mentioned results suggest that a thermal treatment to the ceria nanocubes can improve the multienzyme-mimic activities, with and without Pr modification. Herein, the effect of Pr-doping will be discussed considering specifically how the oxidation treatment at 600 ${ }^{\circ} \mathrm{C}$ can significantly enhance the activity by altering the bulk structure regularity and inducing surface nanofaceting. The possible roles of oxygen vacancies, $\mathrm{Ce}^{3+}$ and $\mathrm{Pr}^{3+}$ defects, and band gap energy are considered and discussed. Possible mechanisms of ceria nanocubes performing different biomimetic functions are also proposed.

4.1. Mechanism of the Multienzyme-Mimic Activities. It is well-known that the redox, in the form of oxidizing and reducing, properties of ceria is closely related to oxygen vacancies $\left(\mathrm{VO}^{\bullet \bullet}\right)$ and reactive oxygen species (ROS). Numerous studies ${ }^{1,2,4}$ have shown that oxygen species and oxygen vacancies are crucial in ceria-based nanozyme performance, such as the role of superoxide $\mathrm{O}_{2}{ }^{\bullet-}$ for oxidase-like ${ }^{53}$ and the hydroxyl radical $\left(\mathrm{OH}^{\bullet}\right)$ scavenging activities. ${ }^{18}$ In the face centered cubic fluorite $\mathrm{CeO}_{2}$ structure, $\mathrm{Ce}^{4+}$ cations are coordinated by eight oxygen atoms, whereas oxygen atoms are tetrahedrally linked with cerium atoms. With the formation of $\mathrm{Ce}^{3+}$ or incorporation of $\mathrm{Pr}^{3+}, \mathrm{Ce}^{4+}$ cations in the lattice are replaced by the trivalent $\mathrm{Ce}^{3+}$ or $\operatorname{Pr}^{3+}$ cations. The oxygen coordination number is decreased to seven to maintain the charge neutrality and stoichiometry of bulk ceria. The removed oxygen generates a $\mathrm{VO}^{\bullet \bullet}$ in the crystalline structure of ceria. The concentration of $\mathrm{VO}^{\bullet \bullet}$ directly influences the oxygen diffusion and migration to the surface, which consequently affect the oxygen availability, oxygen regeneration capacity, and thus redox kinetics on the surface of the catalysts.

The oxidase-like activity, that is, the oxidizing capability, of ceria has been reported previously. ${ }^{21,53}$ During the reaction, it was found that the main intermediate is superoxide $\mathrm{O}_{2}{ }^{\bullet-} .53$ The dissolved $\mathrm{O}_{2}$ molecules can be adsorbed on the surface of ceria nanocubes, and a $4 \mathrm{f}$ electron feedbacks to the $\pi 2 \mathrm{p} *$ orbital of $\mathrm{O}_{2}$ to form a superoxide $\mathrm{O}_{2}{ }^{\bullet-} \cdot \mathrm{O}_{2}{ }^{\bullet-}$ continues to oxidize TMB into blue-colored ox-TMB. The simplified pathway can be explained in the form of an electronic band diagram in Figure 7a. Based on eqs 2 and 3 and using $E_{\mathrm{g}}=3.5$ $\mathrm{eV}$ (energy of direct band gap of $\mathrm{CeO}_{2} \mathrm{NC}$ in Table 2), the valence band energy $E_{\mathrm{VB}}$ of $\mathrm{CeO}_{2} \mathrm{NC}$ can be calculated to be $2.81 \mathrm{eV}$, in which $\chi=5.56 \mathrm{eV}$ is the absolute electronegativity (AEN) of $\mathrm{CeO}_{2}$ and $E^{\mathrm{C}}=4.5 \mathrm{eV}$ is the scaling factor relating
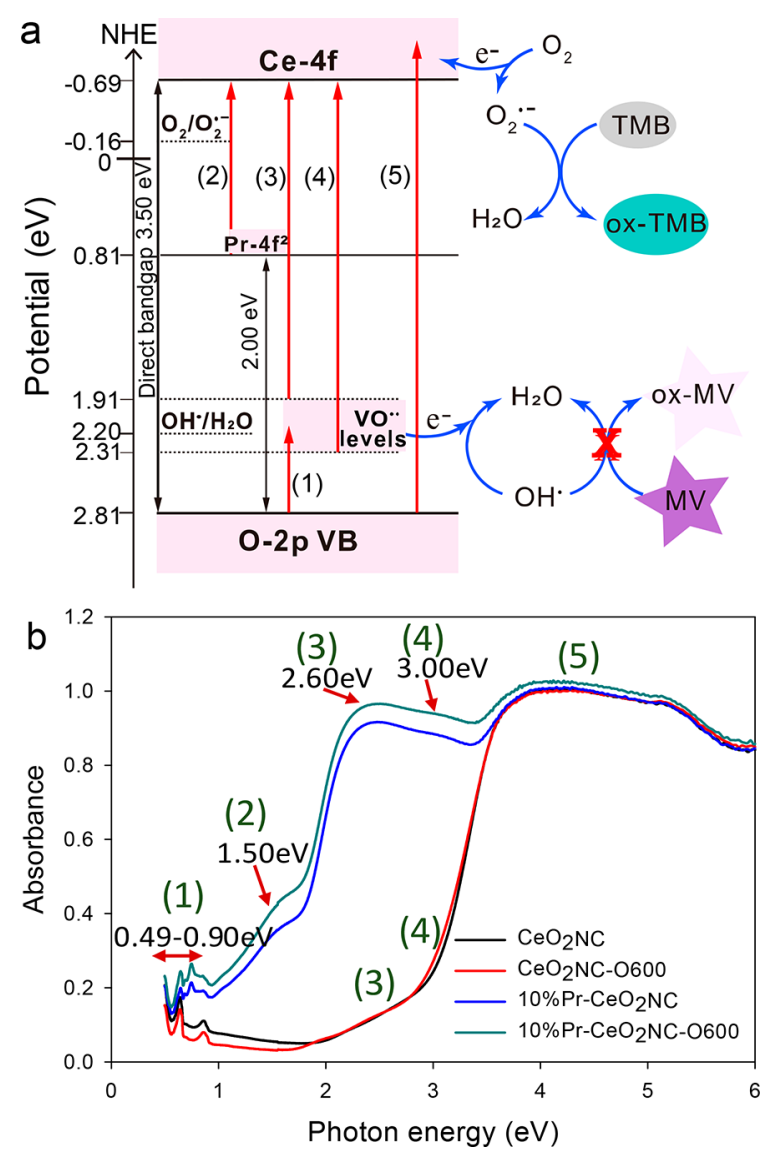

Figure 7. (a) Energy level diagram and excitation processes of pure and Pr-doped $\mathrm{CeO}_{2}$ nanocubes; (b) absorbance spectra of $\mathrm{CeO}_{2} \mathrm{NC}$ and $10 \%$ Pr- $\mathrm{CeO}_{2} \mathrm{NC}$ samples with and without $600{ }^{\circ} \mathrm{C}$ oxidation treatment.

the normal hydrogen electrode scale (NHE) to the absolute vacuum scale. $^{21}$

$$
\begin{aligned}
& E_{\mathrm{CB}}=\chi-E^{\mathrm{C}}-0.5 E_{\mathrm{g}} \\
& E_{\mathrm{g}}=E_{\mathrm{VB}}-E_{\mathrm{CB}}
\end{aligned}
$$

Generally, the energy levels of adsorbed and potentially formed ROS can be approximated by their standard redox potential $E_{0}$. The feasibility of electron transfers between ceria and adsorbed ROS can be determined by the relative energy position of $E_{\mathrm{VB}}, E_{\mathrm{CB}}$ and $E_{0}$. In aqueous media, the redox potential $E_{0}$ for the dissolved $\mathrm{O}_{2} / \mathrm{O}_{2}{ }^{\bullet-}$ couple is $-0.16 \mathrm{eV}$, while it is $2.2 \mathrm{eV}$ for the $\mathrm{OH}^{\bullet} / \mathrm{H}_{2} \mathrm{O}$ couple. ${ }^{54}$

Because $E_{\mathrm{CB}}$ of ceria $(-0.69 \mathrm{eV})$ is more negative than the potential of $\mathrm{O}_{2} / \mathrm{O}_{2}{ }^{--}(-0.16 \mathrm{eV})$, the conduction band electrons are good reductants, so that $\mathrm{O}_{2}$ can be reduced to generate $\mathrm{O}_{2}^{\bullet-}$, which consequently oxidizes TMB. Furthermore, Pr-doping in $\mathrm{CeO}_{2}$ can create excited $f$-energy states in the midband as elucidated in the optical absorption spectra of Figure $7 \mathrm{a}$. The distance between the top of the O $2 \mathrm{p} \mathrm{VB}$ and $\operatorname{Pr} 4 \mathrm{f}^{2}$ band according to the calculated direct band gap energy for $\operatorname{Pr}_{6} \mathrm{O}_{11}$ is $2 \mathrm{eV}$ (Figure S7), resulting in the narrowing of band gap. The energy state of the $\operatorname{Pr} 4 \mathrm{f}^{2}$ band can trap electrons from $\mathrm{O}_{2}$ easily, which is one of the reasons why $10 \%$ $\mathrm{Pr}-\mathrm{CeO}_{2} \mathrm{NC}$ is more active as oxidase-mimic than pure ceria nanocubes as shown in Figure 6a,b. 


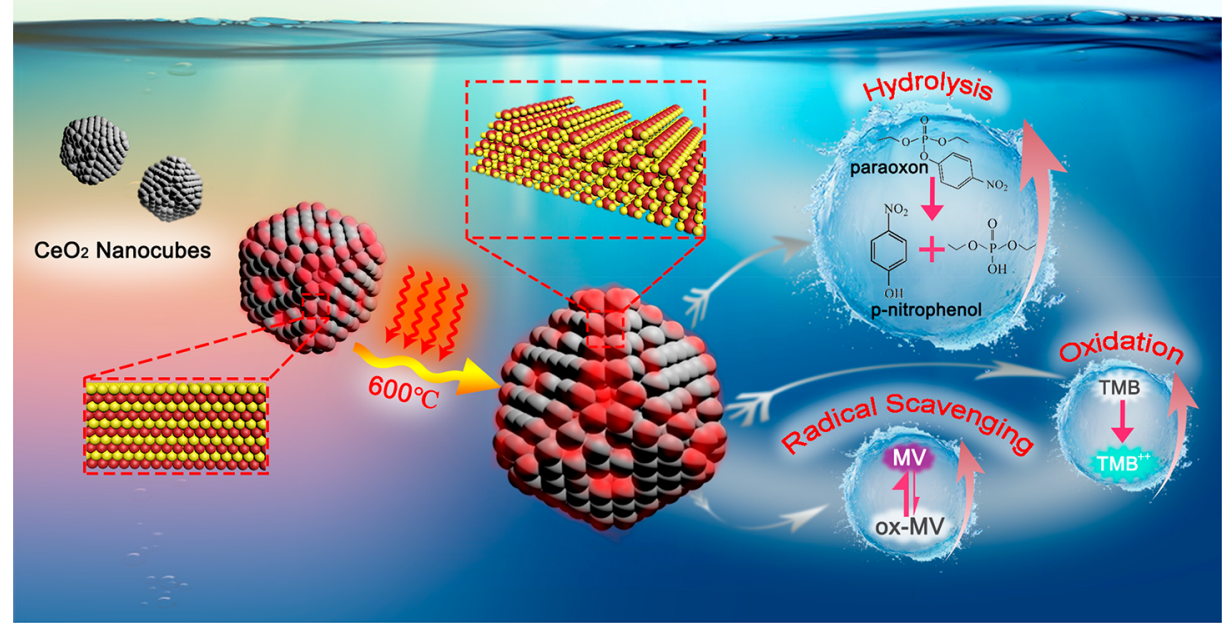

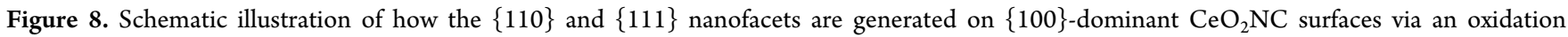
treatment at $600{ }^{\circ} \mathrm{C}$, which consequently enhance their biomimetic enzyme activities.

Meanwhile, oxygen vacancies in ceria nanocubes may explain the hydroxyl radical scavenging activity. According to Choudhury et al., ${ }^{32}$ oxygen vacancies are located between the band gaps of $\mathrm{Ce} 4 \mathrm{f}$ and $\mathrm{O} 2 \mathrm{p}$, in the band gap of $\mathrm{CeO}_{2}$, again this intermediate defect energy level results in the narrowing the band gaps. The level of oxygen vacancies can be estimated from the photon energy profile based on UV-vis absorbance data in Figure 3. As shown in Figure 7b, each absorption band can be associated with an electron transition between two energy states in Figure 7a. For example, the absorption bands centered at 2.6 and $3 \mathrm{eV}$, i.e., 1.91 and $2.31 \mathrm{eV}$ vs NHE, could be assigned to the charge transfer transition from oxygen vacancies to $\mathrm{Ce} 4 \mathrm{f} \mathrm{CB}$. The intensity of these peaks is higher for Pr-doped sample due to the Pr presence which promotes the production of oxygen vacancies. The standard redox potential $E_{0} \mathrm{OH}^{\bullet} / \mathrm{H}_{2} \mathrm{O}$ couple is $2.2 \mathrm{eV},{ }^{54}$ and the $\mathrm{OH}^{\bullet}$ radicals generated from the Fenton reaction can be reduced to $\mathrm{H}_{2} \mathrm{O}$ by accepting electrons from the $\mathrm{VO}^{\bullet \bullet}$ band. It has been previously reported that the redox state of ceria nanoparticles would not change with $\mathrm{pH}^{55}$ therefore, redox potentials are quoted at neutral $\mathrm{pH}$, although the oxidation and antioxidant experiments took place in more acidic conditions.

The reaction chemistry for phosphatase-mimic activity of ceria was reported to do with the mixed $\mathrm{Ce}^{3+} / \mathrm{Ce}^{4+}$ oxidation states. The surface $\mathrm{Ce}^{4+}$ ions allow the binding of paraoxon because of the polar nature of phosphoryl oxygen, meanwhile $\mathrm{Ce}^{3+}$ would facilitate the selective adsorption of $\mathrm{H}_{2} \mathrm{O}$. Consequently, the steric coordination enables an efficient nucleophilic attack of water at the phosphorus center of paraoxon and hence the $\mathrm{P}-\mathrm{O}$ bond cleavage. It implies that the concentration of $\mathrm{Ce}^{3+}-\mathrm{O}-\mathrm{Ce}^{4+}$ defect sites as well as oxygen vacancies that are coordinately unsaturated are important in the hydrolysis of toxic paraoxon. Although both $\mathrm{Pr}$ and $\mathrm{Ce}$ are rare earth metals known for forming numerous nonstoichiometric oxides, their stable phases are different, $\mathrm{CeO}_{2}$ for $\mathrm{Ce}$ and $\mathrm{Pr}_{6} \mathrm{O}_{11}$ for Pr. It means that varying ratios of $\mathrm{Ce}^{3+} / \mathrm{Ce}^{4+}$ or $\mathrm{Pr}^{3+} / \mathrm{Pr}^{4+}$ together with the corresponding oxygen vacancies to balance the charges. Therefore, it is expected that doping $\mathrm{CeO}_{2}$ with $\mathrm{Pr}$ should increase the total trivalent ions concentration as well as the $\mathrm{VO}^{\bullet \bullet}$ concentration, which was confirmed by the Raman peak at $572 \mathrm{~cm}^{-1}$ (Figure
4). In addition, XPS results indicate that all Pr species on the surface of $10 \% \mathrm{Pr}-\mathrm{CeO}_{2} \mathrm{NC}$ are $\mathrm{Pr}^{3+}$, while only a small amount of $\mathrm{Pr}^{4+}$ can be found for the oxidized $10 \% \mathrm{Pr}^{-\mathrm{CeO}_{2} \mathrm{NC}-\mathrm{O} 600}$ sample. It also should be mentioned that the incorporation of Pr to ceria nanocubes enhances the redox property of pure ceria nanocubes, as shown in the TPR results (Figure 5), which also is favorable to redox $\mathrm{Ce}^{3+} / \mathrm{Ce}^{4+}$ and $\mathrm{Pr}^{3+} / \mathrm{Pr}^{4+}$ couple cycles and then improves the phosphatase-mimic activity of ceria nanocubes. All these effects contribute to the enhanced hydrolysis efficiency of phosphatase-like activity of $10 \% \mathrm{Pr}$ $\mathrm{CeO}_{2} \mathrm{NC}$.

4.2. Influence of Oxidation Treatment at $600{ }^{\circ} \mathrm{C}$. In general, the biomimetic enzyme activity results in Figure 6 show that the oxidized ceria nanocube samples exhibit higher capability in imitating oxidase, hydroxyl radical scavenger, and phosphatase than the untreated NCs. After discussion of the possible mechanism of ceria acting as three types of artificial enzymes, the influence of thermal oxidation $\left(5 \% \mathrm{O}_{2} / \mathrm{He}\right.$ at 600 ${ }^{\circ} \mathrm{C}$ for $1 \mathrm{~h}$ ) on ceria's nanocube structure and biomimetic enzyme activities and their correlation are considered and shown in Figure 8.

As deduced from TEM, XPS, and XRD results, most of the bulk properties of the samples, such as lattice parameter, $\mathrm{Pr}$ concentration, and $\mathrm{Ce}^{3+} / \mathrm{Ce}^{4+}$ ratio, are almost the same after thermal treatment (Table 1). There is, indeed, a crystal size increase and, consequently, a BET specific surface area drop, which is probably due to the heat-induced aggregation. The most remarkable structure change is the facet restructuring on the crystal surface, including the facet percentage change and the development of sawtoothlike nanofacets (Figure 1 and Figure S3). After oxidation at $600{ }^{\circ} \mathrm{C}$, the percentage of $\{110\}$ increases dramatically, $50 \%$ for $\mathrm{CeO}_{2} \mathrm{NC}$ and $118 \%$ for $10 \%$ Pr-CeO ${ }_{2}$ NC. At the same time, the proportion of $\{100\}$ reduces together with negligible change of $\{111\}$ (inset table in Figure 1). This is reasonable because the $\{100\}$ surface is a polar surface and not stable upon heating. ${ }^{56,57}$ Oxidation at $600{ }^{\circ} \mathrm{C}$ leads to relaxation from $\{100\}$ facets to low energy $\{110\}$ and $\{111\}$ facets, which often appear with defects.

The restructuring of the surface into nanofacets can cause a series of effects. The first is the change of crystallographic termination groups. For instance, it was known that the density 
of oxygen atom varies on different ceria facets, following the order $\{111\}\left(15.8 / \mathrm{nm}^{2}\right)>\{100\}\left(13.7 / \mathrm{nm}^{2}\right)>\{110\}(9.7 /$ $\left.\mathrm{nm}^{2}\right) .{ }^{58}$ So more clustered defect sites are expected on $\{110\}$ than on $\{100\}$. This is confirmed by previous UV Raman results that nanorods with exposed $\{110\}$ and $\{100\}$ surfaces have the most defect sites, followed by nanocubes with $\{100\}$ and nano-octahedra with $\{111\} .{ }^{43}$ The difference in defect sites results in changes in the stability and reactivity of $\mathrm{O}_{2}$ or ROS adsorbed on the nanocrystal surface. Density functional theory calculation showed that the binding energy of superoxide $\mathrm{O}_{2}{ }^{--}$on ceria $\{110\}$ surface is much larger than those of other surfaces. ${ }^{59,60}$ In this study, both $\mathrm{CeO}_{2} \mathrm{NC}-\mathrm{O} 600$ and $10 \% \mathrm{Pr}-\mathrm{CeO}_{2} \mathrm{NC}-\mathrm{O} 600$ have increased proportion of $\{110\}$ facets. This may account for their increased oxidase-like behavior in the TMB oxidation experiment.

Another change of surface termination on different facets is related to Ce atoms. Ce cations are more exposed on the $\{110\}$ surface than on the O-terminated facets of the $\{100\}$ surface. As discussed in section 4.1, the phosphatase-like activity of ceria surface origins from the $\mathrm{Ce}^{3+}$-bound water initiating the nucleophilic attack at the phosphorus center of $\mathrm{Ce}^{4+}$-bound paraoxon. Therefore, the increase of exposed $\mathrm{Ce}$ would facilitate the reaction kinetics, that is, a boost of the phosphatase-like activity.

The final effect is about the increased level of oxygen vacancies in the oxidized ceria samples, based on UV-visible (Figure 3) and Raman spectra (Figure 4). The higher presence of oxygen vacancies provides more freedom for the movement of lattice oxygen and hence increases oxygen mobility in ceria, i.e., its capability to buffer oxygen. ${ }^{19,61}$ Theoretical calculation has predicted that the oxygen vacancy formation energy on ceria follows the order $\{110\}<\{100\}<\{111\} .^{62}$ In other words, $\mathrm{VO}^{\bullet \bullet}$ is the easiest to form on $\{110\}$. Hence it is likely that the oxidized ceria nanocubes with higher ratio of $\{110\}$ has more oxygen vacancies to intermediate the redox reactions.

The nature of the defect sites is critical for understanding the catalysis and the oxidation-induced activity enhancement. The defects in ceria have been discussed in many previous studies. Some attribute them to the presence of $\mathrm{Ce}^{3+}$ while others relate them with oxygen vacancies. In this study, XPS spectra of our four ceria nanocubes (Figure S6) show that Ce 3d profiles are very similar. Further calculation indicates that even if there is $\mathrm{Ce}^{3+}$ present on the surface, the amount of $\mathrm{Ce}^{3+}$ is small $(<9 \%)$ and similar on the four different ceria nanocubes. In other words, it seems that $\mathrm{Ce}^{3+} / \mathrm{Ce}^{4+}$ ratio has insignificant correlation to the observed trend in our study. This is in contrast to some previous studies such as Celardo et al. ${ }^{22}$ showing that $\mathrm{Ce}^{3+} / \mathrm{Ce}^{4+}$ ratio is crucial in Sm-doped nanoceria as antioxidant, but agrees with other research results where nanoceria with little or similar $\mathrm{Ce}^{3+}$ percentage but different morphology could have dramatic different catalytic activities. ${ }^{18,21,63,64}$ However, it should be highlighted that on the Prdoped ceria nanocube samples, $100 \% \mathrm{Pr}$ is in the oxidation state of $\mathrm{Pr}^{3+}$ as shown in XPS results, that is $10 \%$ to the total $\mathrm{Ce}$ and $\mathrm{Pr}$ amounts. Similar to Ce, the redox $\mathrm{Pr}^{3+} / \mathrm{Pr}^{4+}$ cycle can also be considered as an oxygen buffer. Hence, the total amount of $\mathrm{Ce}^{3+}$ and $\mathrm{Pr}^{3+}$ on $10 \% \mathrm{Pr}-\mathrm{CeO}_{2} \mathrm{NC}$ is $12 \%$, which is slightly higher than in the pure $\mathrm{CeO}_{2} \mathrm{NC}$ sample. For the oxidized $10 \%$ Pr- $\mathrm{CeO}_{2} \mathrm{NC}-\mathrm{O} 600$ sample, only a small amount of $\mathrm{Pr}^{4+}$ was observed according to XPS results. This suggests that there is slightly less than $10 \% \operatorname{Pr}^{3+}$ in this sample. In any case, in this study the vacancy-interstitial (Frenkel-type) oxygen defects cannot be excluded to explain our results. ${ }^{43,65,66}$
The intrinsic Frenkel-type defect is believed to form when some oxygen in ceria migrates from the tetrahedral site to the octahedral site, leaving vacancies in the tetrahedral sites. It is proposed that the interstitial oxygen ions are the "active" species that provide necessary oxygen mobility, which is crucial in the function of ceria as a catalyst. Mamontov et al. ${ }^{65}$ showed that for pure $\mathrm{CeO}_{2}$ both oxygen vacancies and the interstitial oxygen ion concentration, as well as the total oxygen defect concentration, increase with temperature until they reach the maximum at $\sim 600{ }^{\circ} \mathrm{C}$. Another separate study on the dephosphorylation reaction of several nucleotides like adenosine triphosphate by ceria particles showed that the most effective ceria are those calcined at $600{ }^{\circ} \mathrm{C} .{ }^{67}$ These results are consistent with the influence of oxidation of ceria nanocubes with and without Pr doping observed in this study.

In summary, the oxidation treatment leads to the formation of the Frenkel-type oxygen defects, surface restructuring, and changes of surface facets. Therefore, it causes the reactivity of adsorbed oxygen species to increase, an increase of the oxygen vacancy concentration, and more exposed $\mathrm{Ce}^{3+}$, which eventually result in the activity enhancement of $\mathrm{CeO}_{2}$ nanocubes as oxidase, hydroxyl radical scavenger, and phosphatase, respectively. It is worth noting that the majority of previous work on ceria as an artificial enzyme uses polycrystalline nanoceria. It is known that different crystal planes of ceria exhibit different surface structures, interactions, and catalytic efficiencies. Furthermore, the knowledge based on polycrystalline ceria is merely a collective average from different facets, which makes it difficult to correlate to the catalytic behavior. This study on restructured nanofacets helps us to gain fundamental understanding of ceria's biomimetic function, which could potentially provide support for designing a better ceria-based nanozyme.

\section{CONCLUSIONS}

An oxidation treatment was established for $\{100\}$-dominant pure and Pr-doped ceria NCs with well-defined structures and surfaces to achieve a significant increase in their $\{110\}$ and $\{111\}$ nanofacets. More importantly, without changing most of the bulk properties, and despite the drop in BET specific surface area, such treatment results in a remarkable boost of their artificial enzyme activities imitating oxidase, hydroxyl radical scavenger, and phosphatase. This might be due to the thermally generated $\{110\}$ nanofaceting and increased level of Frenkel-type oxygen defects, which facilitate the oxygen mobility and the formation of oxygen vacancies on the surface. This is very interesting because the seemly contradictory (oxidizing and reducing) behaviors can both be enhanced by an oxidation treatment. It offers a new approach, to the best of our knowledge, the first time reported, to improve the intrinsic enzymatic activity of nanoceria. Considering the wide application of ceria as an artificial enzyme, this simple process may provide great support for designing a high efficiency nanozyme without the change of crystal composition. It may even be extended to other metal-oxide based nanozymes, which is worthy of further investigation.

\section{ASSOCIATED CONTENT}

\section{Supporting Information}

The Supporting Information is available free of charge at https://pubs.acs.org/doi/10.1021/acsami.1c09992. 
TEM or STEM-HAADF images, Ce and Pr element maps and particle size distribution of pure and Pr-doped ceria nanocubes, XRD patterns, XPS spectra of Ce 3d and $\operatorname{Pr} 3 \mathrm{~d}$, band gap energy determination of the samples by the Tauc method, artificial enzyme activities of oxidase, hydroxyl radical scavenger and phosphatase normalized by the BET specific surface area, role of catalase in hydroxyl radical removal, and NCs' performance comparison with $\mathrm{Ce}$ ions (PDF)

\section{AUTHOR INFORMATION}

\section{Corresponding Authors}

Xiaowei Chen - Departamento de Ciencia de los Materiales, Ingeniería Metalúrgica y Química Inorgánica, Facultad de Ciencias and Instituto Universitario de Investigación en Microscopía Electrónica y Materiales (IMEYMAT), Universidad de Cádiz, Puerto Real, Cádiz E-11510, Spain; ○ orcid.org/0000-0001-6426-5399; Email: xiaowei.chen@ uca.es

Lei Jiang - Heavy Oil State Laboratory and Center for Bioengineering and Biotechnology, College of Chemical Engineering, China University of Petroleum (East China), Qingdao 266580, China; o orcid.org/0000-0002-00138590; Email: leijiang@upc.edu.cn

\section{Authors}

Miguel Tinoco - Departamento de Ciencia de los Materiales, Ingeniería Metalúrgica y Química Inorgánica, Facultad de Ciencias, Universidad de Cádiz, Puerto Real, Cádiz E-11510, Spain; orcid.org/0000-0003-2490-8059

Susana Fernández-García - Departamento de Ciencia de los Materiales, Ingeniería Metalúrgica y Química Inorgánica, Facultad de Ciencias, Universidad de Cádiz, Puerto Real, Cádiz E-11510, Spain; 이잉.org/0000-0001-6020-9963

Yujiao Sun - Heavy Oil State Laboratory and Center for Bioengineering and Biotechnology, College of Chemical Engineering, China University of Petroleum (East China), Qingdao 266580, China

Mariia Traviankina - Heavy Oil State Laboratory and Center for Bioengineering and Biotechnology, College of Chemical Engineering, China University of Petroleum (East China), Qingdao 266580, China; O orcid.org/0000-0003-21666613

Pengli Nan - Heavy Oil State Laboratory and Center for Bioengineering and Biotechnology, College of Chemical Engineering, China University of Petroleum (East China), Qingdao 266580, China

Qi Xue - Heavy Oil State Laboratory and Center for Bioengineering and Biotechnology, College of Chemical Engineering, China University of Petroleum (East China), Qingdao 266580, China

Huiyan Pan - Departamento de Ciencia de los Materiales, Ingeniería Metalúrgica y Química Inorgánica, Facultad de Ciencias, Universidad de Cádiz, Puerto Real, Cádiz E-11510, Spain; Henan Key Laboratory of Industrial Microbial Resources and Fermentation Technology, College of Biological and Chemical Engineering, Nanyang Institute of Science and Technology, Nanyang 473004, China; (1) orcid.org/00000002-2511-3082

Almudena Aguinaco - Departamento de Física de la Materia Condensada, Facultad de Ciencias and Instituto Universitario de Investigación en Microscopía Electrónica y Materiales
(IMEYMAT), Universidad de Cádiz, Puerto Real, Cádiz E11510, Spain; 이이이.org/0000-0001-8447-1325

Juan M. González-Leal - Departamento de Física de la Materia Condensada, Facultad de Ciencias and Instituto Universitario de Investigación en Microscopía Electrónica y Materiales (IMEYMAT), Universidad de Cádiz, Puerto Real, Cádiz E-11510, Spain; (1) orcid.org/0000-0003-1077-2197

Ginesa Blanco - Departamento de Ciencia de los Materiales, Ingeniería Metalúrgica y Química Inorgánica, Facultad de Ciencias and Instituto Universitario de Investigación en Microscopía Electrónica y Materiales (IMEYMAT), Universidad de Cádiz, Puerto Real, Cádiz E-11510, Spain; (1) orcid.org/0000-0003-3242-1339

Eduardo Blanco - Departamento de Física de la Materia Condensada, Facultad de Ciencias and Instituto Universitario de Investigación en Microscopía Electrónica y Materiales (IMEYMAT), Universidad de Cádiz, Puerto Real, Cádiz E11510, Spain; ㅇo이.org/0000-0002-2234-1477

Ana B. Hungría - Departamento de Ciencia de los Materiales, Ingeniería Metalúrgica y Química Inorgánica, Facultad de Ciencias and Instituto Universitario de Investigación en Microscopía Electrónica y Materiales (IMEYMAT), Universidad de Cádiz, Puerto Real, Cádiz E-11510, Spain; (1) orcid.org/0000-0002-4622-6967

Jose J. Calvino - Departamento de Ciencia de los Materiales, Ingeniería Metalúrgica y Química Inorgánica, Facultad de Ciencias and Instituto Universitario de Investigación en Microscopía Electrónica y Materiales (IMEYMAT), Universidad de Cádiz, Puerto Real, Cádiz E-11510, Spain; (1) orcid.org/0000-0002-0989-1335

Complete contact information is available at:

https://pubs.acs.org/10.1021/acsami.1c09992

\section{Author Contributions}

The manuscript was written through contributions of all authors. All authors have given approval to the final version of the manuscript.

\section{Notes}

The authors declare no competing financial interest.

\section{ACKNOWLEDGMENTS}

This work has been supported by the Ministry of Science, Innovation and Universities of Spain with Reference Numbers of ENE2017-82451-C3-2-R, MAT2016-81118-P and MAT2017-87579-R. The research projects funded by the Natural Science Foundation of Shandong Province (Grant ZR2017LB028), Key R\&D Program of Shandong Province (Grant 2018GSF118032), and Fundamental Research Funds for the Central Universities (Grant 18CX02125A) in China are also acknowledged. TEM/STEM data were obtained at DMEUCA node of the Spanish Unique Scientific and Technological Infrastructure (ICTS) of Electron Microscopy of Materials ELECMIM. M. Tinoco thanks the FPU Scholarship Program (Grant AP2010-3737) from Ministry of Education of Spain. H. Pan is grateful for financial support (Grant 201406140130) from the Chinese Scholarship Council to accomplish her Ph.D. study at the University of Cadiz (Spain). J. M. González, G. Blanco, and X. Chen are also grateful for the financial support from the joint project (Proyectos Integradores, Grant PI20201) in IMEYMAT of the University of Cadiz. 


\section{REFERENCES}

(1) Wang, X.; Guo, W.; Hu, Y.; Wu, J.; Wei, H. Nanozymes: Next Wave of Artificial Enzymes; Springer, 2016; pp 1-6.

(2) Wei, H.; Wang, E. Nanomaterials with Enzyme-like Characteristics (Nanozymes): Next-Generation Artificial Enzymes. Chem. Soc. Rev. 2013, 42, 6060-6093.

(3) Lin, Y.; Ren, J.; Qu, X. Catalytically Active Nanomaterials: A Promising Candidate for Artificial Enzymes. Acc. Chem. Res. 2014, 47, 1097-1105.

(4) Xu, C.; Qu, X. Cerium Oxide Nanoparticle: A Remarkably Versatile Rare Earth Nanomaterial for Biological Applications. NPG Asia Mater. 2014, 6, No. e90.

(5) He, W.; Zhou, Y.; Wamer, W. G.; Hu, X.; Wu, X.; Zheng, Z.; Boudreau, M. D.; Yin, J. Intrinsic Catalytic Activity of $\mathrm{Au}$ Nanoparticles with Respect to Hydrogen Peroxide Decomposition and Superoxide Scavenging. Biomaterials 2013, 34, 765-773.

(6) Gao, L.; Zhuang, J.; Nie, L.; Zhang, J.; Zhang, Y.; Gu, N.; Wang, T.; Feng, J.; Yang, D.; Perrett, S.; Yan, X. Intrinsic Peroxidase-like Activity of Ferromagnetic Nanoparticles. Nat. Nanotechnol. 2007, 2, 577-583.

(7) Gao, L.; Fan, K.; Yan, X. Iron Oxide Nanozyme: A Multifunctional Enzyme Mimetic for Biomedical Applications. Theranostics 2017, 7, 3207-3227.

(8) Song, Y.; Wang, X.; Zhao, C.; Qu, K.; Ren, J.; Qu, X. Label-free Colorimetric Detection of Single Nucleotide Polymorphism by Using Single-walled Carbon Nanotube Intrinsic Peroxidase-like Activity. Chem. - Eur. J. 2010, 16, 3617-3621.

(9) Asati, A.; Santra, S.; Kaittanis, C.; Nath, S.; Perez, J. M. OxidaseLike Activity of Polymer-Coated Cerium Oxide Nanoparticles. Angew. Chem., Int. Ed. 2009, 48, 2308-2312.

(10) Vernekar, A. A.; Das, T.; Mugesh, G. Vacancy-Engineered Nanoceria: Enzyme Mimetic Hotspots for the Degradation of Nerve Agents. Angew. Chem., Int. Ed. 2016, 55, 1412-1416.

(11) Liu, H.; Liu, J. Self-Limited Phosphatase-Mimicking $\mathrm{CeO}_{2}$ Nanozymes. ChemNanoMat 2020, 6, 947-952.

(12) Kuah, E.; Toh, S.; Yee, J.; Ma, Q.; Gao, Z. Enzyme Mimics: Advances and Applications. Chem. - Eur. J. 2016, 22, 8404-8430.

(13) Karakoti, A. S.; Singh, S.; Kumar, A.; Malinska, M.; Kuchibhatla, S. V. N. T.; Wozniak, K.; Self, W. T.; Seal, S. PEGylated Nanoceria as Radical Scavenger with Tunable Redox Chemistry. J. Am. Chem. Soc. 2009, 131, 14144-14145.

(14) Asati, A.; Kaittanis, C.; Santra, S.; Perez, J. M. pH-Tunable Oxidase-Like Activity of Cerium Oxide Nanoparticles Achieving Sensitive Fluorigenic Detection of Cancer Biomarkers at Neutral pH. Anal. Chem. 2011, 83, 2547-2553.

(15) Lord, M. S.; Tsoi, B.; Gunawan, C.; Teoh, W. Y.; Amal, R.; Whitelock, J. M. Anti-Angiogenic Activity of Heparin Functionalised Cerium Oxide Nanoparticles. Biomaterials 2013, 34, 8808-8818.

(16) Lord, M. S.; Jung, M.; Teoh, W. Y.; Gunawan, C.; Vassie, J. A.; Amal, R.; Whitelock, J. M. Cellular Uptake and Reactive Oxygen Species Modulation of Cerium Oxide Nanoparticles in Human Monocyte Cell Line U937. Biomaterials 2012, 33, 7915-7924.

(17) Korsvik, C.; Patil, S.; Seal, S.; Self, W. T. Superoxide Dismutase Mimetic Properties Exhibited by Vacancy Engineered Ceria Nanoparticles. Chem. Commun. 2007, 1056-1058.

(18) Fernandez-Garcia, S.; Jiang, L.; Tinoco, M.; Hungria, A. B.; Han, J.; Blanco, G.; Calvino, J. J.; Chen, X. Enhanced Hydroxyl Radical Scavenging Activity by Doping Lanthanum in Ceria Nanocubes. J. Phys. Chem. C 2016, 120, 1891-1901.

(19) Wu, Z.; Li, M.; Overbury, S. H. On the Structure Dependence of $\mathrm{CO}$ Oxidation over $\mathrm{CeO}_{2}$ Nanocrystals with Well-Defined Surface Planes. J. Catal. 2012, 285, 61-73.

(20) Mai, H.; Sun, L.; Zhang, Y.; Si, R.; Feng, W.; Zhang, H.; Liu, H.; Yan, C. Shape-Selective Synthesis and Oxygen Storage Behavior of Ceria Nanopolyhedra, Nanorods, and Nanocubes. J. Phys. Chem. B 2005, 109, 24380-24385.

(21) Jiang, L.; Fernandez-Garcia, S.; Tinoco, M.; Yan, Z.; Xue, Q.; Blanco, G.; Calvino, J. J.; Hungria, A. B.; Chen, X. Improved Oxidase
Mimetic Activity by Praseodymium Incorporation into Ceria Nanocubes. ACS Appl. Mater. Interfaces 2017, 9, 18595-18608.

(22) Celardo, I.; De Nicola, M.; Mandoli, C.; Pedersen, J. Z.; Traversa, E.; Ghibelli, L. Ce ${ }^{3+}$ Ions Determine Redox-Dependent Anti-Apoptotic Effect of Cerium Oxide Nanoparticles. ACS Nano 2011, 5, 4537-4549.

(23) Fuentes, R. O.; Acuña, L. M.; Leyva, A. G.; Baker, R. T.; Pan, H.; Chen, X.; Delgado-Jaén, J. J. Physicochemical Properties of Nanostructured Pd/Lanthanide-Doped Ceria Spheres with High Catalytic Activity for $\mathrm{CH}_{4}$ Combustion. J. Mater. Chem. A 2018, 6, $7488-7499$.

(24) Giménez-Mañogil, J.; Guillén-Hurtado, N.; Fernández-García, S.; Chen, X.; Calvino-Gámez, J. J.; García-García, A. CeriaPraseodymia Mixed Oxides: Relationships between Redox Properties and Catalytic Activities towards NO Oxidation to $\mathrm{NO}_{2}$ and COPROX Reactions. Top. Catal. 2016, 59, 1065-1070.

(25) Yang, Y.; Mao, Z.; Huang, W.; Liu, L.; Li, J.; Li, J.; Wu, Q. Redox Enzyme-Mimicking Activities of $\mathrm{CeO}_{2}$ Nanostructures: Intrinsic Influence of Exposed Facets. Sci. Rep. 2016, 6, 35344.

(26) Tinoco, M.; Fernandez-Garcia, S.; Villa, A.; Gonzalez, J. M.; Blanco, G.; Hungria, A. B.; Jiang, L.; Prati, L.; Calvino, J. J.; Chen, X. Selective Oxidation of Glycerol on Morphology Controlled Ceria Nanomaterials. Catal. Sci. Technol. 2019, 9, 2328-2334.

(27) Tinoco, M.; Fernandez-Garcia, S.; Lopez-Haro, M.; Hungria, A. B.; Chen, X.; Blanco, G.; Perez-Omil, J. A.; Collins, S. E.; Okuno, H.; Calvino, J. J. Critical Influence of Nanofaceting on the Preparation and Performance of Supported Gold Catalysts. ACS Catal. 2015, 5, 3504-3513.

(28) Donarski, W. J.; Dumas, D. P.; Heitmeyer, D. P.; Lewis, V. E.; Raushel, F. M. Structure-Activity Relationships in the Hydrolysis of Substrates by the Phosphotriesterase from Pseudomonas Diminuta. Biochemistry 1989, 28, 4650-4655.

(29) Lin, Y.; Wu, Z.; Wen, J.; Poeppelmeier, K. R.; Marks, L. D. Imaging the Atomic Surface Structures of $\mathrm{CeO}_{2}$ Nanoparticles. Nano Lett. 2014, 14, 191-196.

(30) Crozier, P. A.; Wang, R.; Sharma, R. In Situ Environmental TEM Studies of Dynamic Changes in Cerium-Based Oxides Nanoparticles during Redox Processes. Ultramicroscopy 2008, 108, $1432-1440$

(31) Plakhova, T. V.; Romanchuk, A. Y.; Butorin, S. M.; Konyukhova, A. D.; Egorov, A. V.; Shiryaev, A. A.; Baranchikov, A. E.; Dorovatovskii, P. V.; Huthwelker, T.; Gerber, E.; Bauters, S.; Sozarukova, M. M.; Scheinost, A. C.; Ivanov, V. K.; Kalmykov, S. N.; Kvashnina, K. O. Towards the Surface Hydroxyl Species in $\mathrm{CeO}_{2}$ Nanoparticles. Nanoscale 2019, 11, 18142-18149.

(32) Choudhury, B.; Chetri, P.; Choudhury, A. Oxygen Defects and Formation of $\mathrm{Ce}^{3+}$ Affecting the Photocatalytic Performance of $\mathrm{CeO}_{2}$ Nanoparticles. RSC Adv. 2014, 4, 4663-4671.

(33) Amarsingh Bhabu, K.; Theerthagiri, J.; Madhavan, J.; Balu, T.; Muralidharan, G.; Rajasekaran, T. R. Cubic Fluorite Phase of Samarium Doped Cerium Oxide $\left(\mathrm{CeO}_{2}\right)_{0.96} \mathrm{Sm}_{0.04}$ for Solid Oxide Fuel Cell Electrolyte. J. Mater. Sci.: Mater. Electron. 2016, 27, 15661573.

(34) Bharathi, R. N.; Sankar, S. Structural, Optical and Magnetic Properties of Pr Doped $\mathrm{CeO}_{2}$ Nanoparticles Synthesized by CitrateNitrate Auto Combustion Method. J. Mater. Sci.: Mater. Electron. 2018, 29, 6679-6691.

(35) Yuan, L.; Deng, H.; Li, S.; Wei, S.; Luo, J. Unified Theory of Direct or Indirect Band-Gap Nature of Conventional Semiconductors. Phys. Rev. B: Condens. Matter Mater. Phys. 2018, 98, 245203.

(36) Wang, Z.; Quan, Z.; Lin, J. Remarkable Changes in the Optical Properties of $\mathrm{CeO}_{2}$ Nanocrystals Induced by Lanthanide Ions Doping. Inorg. Chem. 2007, 46, 5237-5242.

(37) Zhang, D.; Ni, X.; Zheng, H.; Zhang, X.; Song, J. Fabrication of Rod-like $\mathrm{CeO}_{2}$ : Characterization, Optical and Electrochemical Properties. Solid State Sci. 2006, 8, 1290-1293.

(38) Tsunekawa, S.; Wang, J.; Kawazoe, Y.; Kasuya, A. Blueshifts in the Ultraviolet Absorption Spectra of Cerium Oxide Nanocrystallites. J. Appl. Phys. 2003, 94, 3654-3656. 
(39) Zhang, H.; Bayne, M.; Fernando, S.; Legg, B.; Zhu, M.; Penn, R. L.; Banfield, J. F. Size-Dependent Bandgap of Nanogoethite. J. Phys. Chem. C 2011, 115, 17704-17710.

(40) Sahoo, S. K.; Mohapatra, M.; Anand, S. Characterization and Optical Properties of Eu-Doped Cubic Nano Ceria Synthesized by Using the Co-Precipitation-Hydrothermal Route. J. Korean Phys. Soc. 2013, 62, 297-304.

(41) Mcbride, J. R.; Hass, K. C.; Poindexter, B. D.; Weber, W. H. Raman and X-Ray Studies of $\mathrm{Ce}_{1-\mathrm{x}} \mathrm{RE}_{\mathrm{x}} \mathrm{O}_{2-\mathrm{y}}$, Where $\mathrm{RE}=\mathrm{La}, \mathrm{Pr}, \mathrm{Nd}$, $\mathrm{Eu}, \mathrm{Gd}$, and Tb. J. Appl. Phys. 1994, 76, 2435-2441.

(42) Li, L.; Hu, G.-S.; Lu, J.-Q.; Luo, M.-F. Review of Oxygen Vacancies in $\mathrm{CeO}_{2}$-Doped Solid Solutions as Characterized by Raman Spectroscopy. Wuli Huaxue Xuebao 2012, 28, 1012-1020.

(43) Wu, Z.; Li, M.; Howe, J.; Meyer, H. M., III; Overbury, S. H. Probing Defect Sites on $\mathrm{CeO}_{2}$ Nanocrystals with Well-Defined Surface Planes by Raman Spectroscopy and $\mathrm{O}_{2}$ Adsorption. Langmuir 2010, 26, 16595-16606.

(44) Silva, I. d. C.; Sigoli, F. A.; Mazali, I. O. Reversible Oxygen Vacancy Generation on Pure $\mathrm{CeO}_{2}$ Nanorods Evaluated by in Situ Raman Spectroscopy. J. Phys. Chem. C 2017, 121, 12928-12935.

(45) Liu, M.; Wu, X.; Liu, S.; Gao, Y.; Chen, Z.; Ma, Y.; Ran, R.; Weng, D. Study of $\mathrm{Ag} / \mathrm{CeO}_{2}$ Catalysts for Naphthalene Oxidation: Balancing the Oxygen Availability and Oxygen Regeneration Capacity. Appl. Catal., B 2017, 219, 231-240.

(46) Pu, Z.; Lu, J.; Luo, M.; Xie, Y. Study of Oxygen Vacancies in $\mathrm{Ce}_{0.9} \mathrm{Pr}_{0.1} \mathrm{O}_{2-\delta}$ Solid Solution by in Situ X-Ray Diffraction and in Situ Raman Spectroscopy. J. Phys. Chem. C 2007, 111, 18695-18702.

(47) Mehmood, R.; Ariotti, N.; Yang, J.; Koshy, P.; Sorrell, C. C. $\mathrm{pH}$-Responsive Morphology-Controlled Redox Behavior and Cellular Uptake of Nanoceria in Fibrosarcoma. ACS Biomater. Sci. Eng. 2018, 4, 1064-1072.

(48) Pirmohamed, T.; Dowding, J. M.; Singh, S.; Wasserman, B.; Heckert, E.; Karakoti, A. S.; King, J. E. S.; Seal, S.; Self, W. T. Nanoceria Exhibit Redox State-Dependent Catalase Mimetic Activity. Chem. Commun. 2010, 46, 2736-2738.

(49) Kuchibhatla, S. V. N. T.; Karakoti, A. S.; Vasdekis, A. E.; Windisch, C. F.; Seal, S.; Thevuthasan, S.; Baer, D. R. An Unexpected Phase Transformation of Ceria Nanoparticles in Aqueous Media. J. Mater. Res. 2019, 34, 465-473.

(50) Kuchibhatla, S. V. N. T.; Karakoti, A. S.; Baer, D. R.; Samudrala, S.; Engelhard, M. H.; Amonette, J. E.; Thevuthasan, S.; Seal, S. Influence of Aging and Environment on Nanoparticle Chemistry: Implication to Confinement Effects in Nanoceria. J. Phys. Chem. C 2012, 116, 14108-14114.

(51) Gaynor, J. D.; Karakoti, A. S.; Inerbaev, T.; Sanghavi, S.; Nachimuthu, P.; Shutthanandan, V.; Seal, S.; Thevuthasan, S. Enzyme-Free Detection of Hydrogen Peroxide from Cerium Oxide Nanoparticles Immobilized on Poly(4-Vinylpyridine) Self-Assembled Monolayers. J. Mater. Chem. B 2013, 1, 3443-3450.

(52) Jiang, L.; Sun, Y.; Chen, Y.; Nan, P. From DNA to Nerve Agents - The Biomimetic Catalysts for the Hydrolysis of Phosphate Esters. ChemistrySelect 2020, 5, 9492-9516.

(53) Cheng, H.; Lin, S.; Muhammad, F.; Lin, Y.; Wei, H. Rationally Modulate the Oxidase-like Activity of Nanoceria for Self-Regulated Bioassays. ACS Sensors 2016, 1, 1336-1343.

(54) He, W.; Jia, H.; Wamer, W. G.; Zheng, Z.; Li, P.; Callahan, J. H.; Yin, J. Predicting and Identifying Reactive Oxygen Species and Electrons for Photocatalytic Metal Sulfide Micro - Nano Structures. J. Catal. 2014, 320, 97-105.

(55) Singh, S.; Dosani, T.; Karakoti, A. S.; Kumar, A.; Seal, S.; Self, W. T. A Phosphate-Dependent Shift in Redox State of Cerium Oxide Nanoparticles and Its Effects on Catalytic Properties. Biomaterials 2011, 32, 6745-6753.

(56) Si, R.; Flytzani-Stephanopoulos, M. Shape and Crystal-Plane Effects of Nanoscale Ceria on the Activity of $\mathrm{Au}-\mathrm{CeO}_{2}$ Catalysts for the Water-Gas Shift Reaction. Angew. Chem., Int. Ed. 2008, 47, 28842887.
(57) Baudin, M.; Wójcik, M.; Hermansson, K. Dynamics, Structure and Energetics of the (111), (011) and (001) Surfaces of Ceria. Surf. Sci. 2000, 468, 51-61.

(58) Madier, Y.; Descorme, C.; Le Govic, A. M.; Duprez, D. Oxygen Mobility in $\mathrm{CeO}_{2}$ and $\mathrm{Ce}_{\mathrm{x}} \mathrm{Zr}_{(1-\mathrm{x})} \mathrm{O}_{2}$ Compounds: Study by $\mathrm{CO}$ Transient Oxidation and ${ }^{18} \mathrm{O} /{ }^{16} \mathrm{O}$ Isotopic Exchange. J. Phys. Chem. B 1999, 103, 10999-11006.

(59) Huang, M.; Fabris, S. Role of Surface Peroxo and Superoxo Species in the Low-Temperature Oxygen Buffering of Ceria: Density Functional Theory Calculations. Phys. Rev. B: Condens. Matter Mater. Phys. 2007, 75, 081404.

(60) Fernández-García, S.; Collins, S. E.; Tinoco, M.; Hungría, A. B.; Calvino, J. J.; Cauqui, M. A.; Chen, X. Influence of $\{111\}$ Nanofaceting on the Dynamics of CO Adsorption and Oxidation over $\mathrm{Au}$ Supported on $\mathrm{CeO}_{2}$ Nanocubes: An Operando DRIFT Insight. Catal. Today 2019, 336, 90-98.

(61) Martin, D.; Duprez, D. Mobility of Surface Species on Oxides. 1. Isotopic Exchange of ${ }^{18} \mathrm{O}_{2}$ with ${ }^{16} \mathrm{O}$ of $\mathrm{SiO}_{2}, \mathrm{Al}_{2} \mathrm{O}_{3}, \mathrm{ZrO}_{2}, \mathrm{MgO}$, $\mathrm{CeO}_{2}$, and $\mathrm{CeO}_{2}-\mathrm{Al}_{2} \mathrm{O}_{3}$. Activation by Noble Metals. Correlation with Oxide Basicity. J. Phys. Chem. 1996, 100, 9429-9438.

(62) Nolan, M.; Parker, S. C.; Watson, G. W. The Electronic Structure of Oxygen Vacancy Defects at the Low Index Surfaces of Ceria. Surf. Sci. 2005, 595, 223-232.

(63) Cafun, J.; Kvashnina, K. O.; Casals, E.; Puntes, V. F.; Glatzel, P. Absence of $\mathrm{Ce}^{3+}$ Sites in Chemically Active Colloidal Ceria Nanoparticles. ACS Nano 2013, 7, 10726-10732.

(64) Fisher, T. J.; Zhou, Y.; Wu, T.; Wang, M.; Soo, Y.; Cheung, C. Structure-Activity Relationship of Nanostructured Ceria for the Catalytic Generation of Hydroxyl Radicals. Nanoscale 2019, 11, $4552-4561$.

(65) Mamontov, E.; Egami, T.; Brezny, R.; Koranne, M.; Tyagi, S. Lattice Defects and Oxygen Storage Capacity of Nanocrystalline Ceria and Ceria-Zirconia. J. Phys. Chem. B 2000, 104, 11110-11116.

(66) Mamontov, E.; Egami, T. Structural Defects in a Nano-Scale Powder of $\mathrm{CeO}_{2}$ Studied by Pulsed Neutron Diffraction. J. Phys. Chem. Solids 2000, 61, 1345-1356.

(67) Janoš, P.; Lovászová, I.; Pfeifer, J.; Ederer, J.; Došek, M.; Loucka, T.; Henych, J.; Kolská, Z.; Milde, D.; Opletal, T. Accelerated Dephosphorylation of Adenosine Phosphates and Related Compounds in the Presence of Nanocrystalline Cerium Oxide. Environ. Sci.: Nano 2016, 3, 847-856. 